\title{
Heparan Sulfate Proteoglycan and Laminin Immunoreactivity on Cultured Astrocytes: Relationship to Differentiation and Neurite Growth
}

\author{
March Dundore Ard and Richard P. Bunge \\ Department of Anatomy and Neurobiology, Washington University School of Medicine, St. Louis, Missouri 63110
}

Extracellular matrix (ECM) produced by Schwann cells is known to promote growth of several types of neurites (Ard et al., 1987). Whether a similar material produced by astrocytes may be available to promote neurite growth during CNS development is now open to question. The present study was undertaken to define conditions under which cultured astrocytes deposit the ECM components laminin and heparan sulfate proteoglycan (HSPG), and to relate this deposition to the ability of astrocytes to support neurite growth. The use of 2 different culture media permitted the growth of astrocytes either with or without these ECM components. Neonatal rat cortical astrocytes were cultured by the method of McCarthy and de Vellis (1980) and studied by immunocytochemistry and electron microscopy. Astrocytes grown in serum-containing medium for 5 or $9 \mathrm{~d}$ after subculturing were shown to have fibrillar patches of ECM containing both HSPG and laminin immunoreactivity. Immunoreactivity for the $\mathbf{2}$ molecules was usually colocalized. In contrast, astrocytes subcultured for $5 \mathrm{~d}$ in defined medium showed no immunocytochemical staining for either laminin or HSPG and had no ECM visible in EM. Formation of stellate processes was increased when cells were grown in defined medium compared with that seen in serum-containing medium, and growth of the population was slower.

In 3 other conditions, attainment of stellate morphological differentiation by the astrocytes was correlated with diminution in immunostaining for ECM components. (1) In older cultures (30-42 d after subculturing), stellate, mitotically quiescent cells showed relatively little HSPG or laminin immunoreactivity. (2) Cultures initially maintained in serumcontaining medium and then converted to defined medium lost much of their immunoreactivity for ECM components and developed longer processes. (3) When neurites from fetal rat dorsal root ganglion explants grew across monolayers of astrocytes in serum-containing medium, diminution of ECM immunostaining and development of stellate processes were seen in areas directly contacted by the neurites.

\footnotetext{
Received July 17, 1987; revised Nov. 27, 1987; accepted Dec. 23, 1987.

We thank Laura Tynan and Margaret Bates for technical assistance, Drs. C. Cornbrooks, L. Eng, C. Gatchalian, J. Hassell, J. Sanes, R. Timpl, and J. Wood for gifts of antibodies, Dr. M. Bunge for advice on EM, Joe Hayes for help with photography, and Susan Mantia for preparation of the manuscript. We appreciate comments on the manuscript from Drs. N. Kleitman, A. Pearlman, and J. Sanes. This work was supported by NIH Grant NS09923 and a fellowship to M. D. A. from the National Multiple Sclerosis Society.

Correspondence should be addressed to Dr. March Ard, Department of Anatomy and Neurobiology, Washington University School of Medicine, 660 South Euclid Avenue, St. Louis, MO 63110.

Copyright (C) 1988 Society for Neuroscience $0270-6474 / 88 / 082844-15 \$ 02.00 / 0$
}

ECM-containing laminin and HSPG did not appear to be necessary for neurites to interact with astrocytes. In defined medium, in which no ECM was detected, dorsal root ganglion neurites were found in contact with astrocyte surfaces rather than on the rat tail collagen substratum on the culture dish.

The 3 major findings of this study are that astrocytes secrete an ECM containing both HSPG and laminin, that expression of these molecules appears to be regulated with morphological differentiation and with contact by neurites, but that the capacity of astrocytes to interact with growing neurites is not dependent on their expression of HSPG and laminin.

A major problem in the study of astrocytes is to define the changes in their functions that take place during maturation. Changes in astrocytes may be the hasis of the failure of axonal regeneration in the mammalian CNS. In the developing brain, initial growth of axon tracts occurs in the presence of immature astrocytes, and axons may even be guided by astrocytes which temporarily form spaces, tunnels, or channels systematically aligned within the brain parenchyma (Singer et al., 1979; Silver and Sidman, 1980; Krayanek and Goldberg, 1981). In contrast, in the adult mammal, regrowth of axon tracts following CNS damage does not occur. Possibly regrowth is blocked by astrocytic scarring (for review, see Reier et al., 1983). Experimental evidence supports the view that regenerative failure is due to the environment within the CNS rather than to any postulated incapacity of CNS neurons to mount a growth response: Regeneration of CNS axons can be induced by grafting peripheral nerve tissuc into adult brain (c.g., Aguayo et al., 1982; Kromer and Cornbrooks, 1985; So and Aguayo, 1985). Furthermore, astrocytes specifically have been pinpointed as a controlling factor in the CNS environment. In studies of regeneration of mouse corpus callosum, implants of embryonic astrocytes were compared with implants consisting of adult astrocytes and other cells which migrated from the host lesion site. Adult axons readily grew across a layer of embryonic, but not adult, astrocytes (Smith et al., 1986). Taken together these observations suggest that astrocytes differentiate from an immature state in which they interact favorably with growing axons to a mature state in which the interaction is no longer permissive for axon growth. Despite the accumulation of suggestive evidence, no altered physical property has yet been described to account for the changed interaction with axons.

Because the peripheral nerve environment, in contrast to the mature CNS, is permissive for axonal regeneration, attention has recently been focused on a salient difference between PNS 

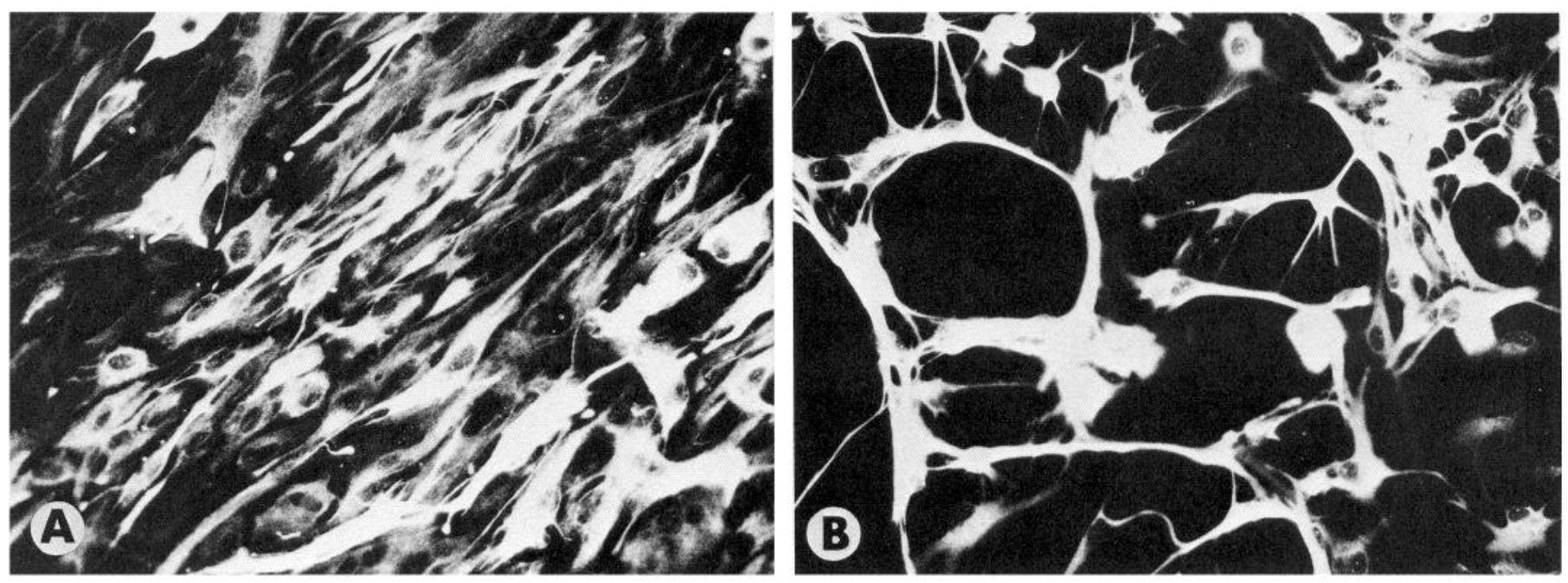

Figure 1. Anti-GFAP immunostaining of astrocytes $5 \mathrm{~d}$ after subculturing. $A$, In medium with serum, most cells are polygonal or flat. B, In defined medium, long, slender processes give most cells a stellate shape. $\times 240$.

and CNS, the production of extracellular matrix (ECM). Schwann cells of the PNS secrete ECM in the form of a basal lamina. This material, as well as one of its constituent molecules, laminin, has been shown to be a strong promoter of neurite growth in vitro (Baron-Van Evercooren et al., 1982; Manthorpe et al., 1983; Rogers et al., 1983; Tomaselli et al., 1986; Ard et al., 1987) and in vivo (Ide et al., 1983; Hall, 1986; Kuffler, 1986). Laminin is secreted by many types of cultured cells in a complex with another basal lamina constituent, heparan sulfate proteoglycan (HSPG), and this complex promotes neurite growth in vitro (Lander et al., 1985; Matthew et al., 1985; Chiu et al., 1986). Immunocytochemical examination of tissue sections has revealed this neurite-promoting ECM complex in PNS but not in CNS (Chiu et al., 1986). In CNS, however, an ECM comparable to the basal lamina of the axon-Schwann cell units of peripheral nerve does not occur except surrounding blood vessels or at the pial surface.

If the lack of ECM in adult mammalian CNS signals its inability to support regeneration, then during the period of developmental axon growth ECM should be present in some form. Indeed, various lines of evidence support this. A loosely organized ECM demonstrable by cationic dyes or colloidal iron labeling has been found in the CNS during development only (Krayanek, 1980; Derer and Nakanishi, 1983; Nakanishi, 1983). Biochemical analysis has shown extracellular hyaluronic acid, present in immature rat brain, to decrease dramatically after 7 d of age (Margolis et al., 1975). Hyaluronectin, a protein defined by its affinity for hyaluronic acid, is more abundant in embryonic than in adult brain and appears to be extracellular (Bignami and Delpech, 1985; Bignami and Dahl, 1986). EM immunocytochemistry has found chondroitin sulfate proteoglycan to be present extracellularly in developing rat brain but only intracellularly in the adult (Aquino et al., 1984a, b). Fibronectin immunoreactivity also has been observed during a limited period of embryonic life in the subplate and marginal zone of mouse cortex (Stewart and Pearlman, 1987) and in rat cerebellum (Hatten et al., 1982; however, negative results were obtained by Schachner et al., 1978; Minier et al., 1981; and Jones et al., 1982). Laminin has been found not as ECM but on the cell surfaces of developing CNS cells in vivo (Liesi, 1985a; how- ever, negative results were obtained by Bignami et al., 1984), and the presence of this neurite-promoting molecule has been correlated with the ability of astrocytes to support regenerative axonal growth (Liesi, 1985b; Ford-Holevinski et al., 1986).

Previous studies in vitro have shown that astrocytes secrete fibronectin (Price and Hynes, 1985) and laminin (Selak et al., 1985 ) into the medium and assemble an ECM containing fibronectin (Vaheri et al., 1976; Kavinsky and Garber, 1979; Liesi et al., 1986) and laminin (Liesi et al., 1983). Through the use of tissue cultures in which growing neurites can be combined with astrocytes, we have investigated the relationship between differentiation of astrocytes, ECM production, and astrocytes' ability to support neurite growth.

\section{Materials and Methods}

Astrocyte cultures. Astrocyte cultures were established from cerebral cortex of 1-d-old rat pups using the method of McCarthy and de Vellis (1980) as modified by Noble et al. (1984). In brief, dissociated cells were grown in a flask for 7-10 d. The flask was then shaken hard overnight on a rotary shaker to remove oligodendrocytes and neurons from their position on the surface of the underlying astrocyte monolayer. After shaking, the purified astrocytes received 2 treatments with $10^{-5}$ m fluorodeoxyuridine to kill any remainder of dividing oligodendrocytes. The medium for the primary cultures was Dulbecco's Modified Eagle's Medium (GIBCO) with 10\% fetal calf serum (Hyclone). For experiments the primary cultures, after 2-8 weeks in vitro, were trypsinized and subcultured onto rat tail collagen-coated $22 \mathrm{~mm}$ glass coverslips or $25 \mathrm{~mm}$ dishes made of Aclar plastic. We compared cells subcultured after 2 weeks in primary culture with cells subcultured after 2 passages and a total of $71 / 2$ weeks in culture. No difference was seen in immunostaining for laminin or HSPG, in ECM observed in EM, or in the ability of the cells to support neurite growth in the subcultures. Therefore, for this study all astrocytes were used within 2 months of primary dissection and with no more than 2 passages. Subculturing was done by adding one drop of cell suspension (covering an area about 5 $\mathrm{mm}$ in diameter) to the center of the dried collagen surface of the coverslip or dish. Plating density was 10,000 astrocytes per drop in medium with serum or 20,000 astrocytes per drop in serum-free medium. Defined medium for subcultured astrocytes was a modification of the N2 medium of Bottenstein and Sato (1979) without HEPES, sodium bicarbonate, or antibiotics, and supplemented with $1.4 \mathrm{mM} \mathrm{L}-$ glutamine, $50 \mu \mathrm{g} / \mathrm{ml} \mathrm{L}$-ascorbic acid, and purified $2.5 \mathrm{~S} \mathrm{NGF} \mathrm{(100} \mathrm{ng/}$ $\mathrm{ml}$; gift of Dr. Eugene Johnson). In some experiments $0.1 \% \mathrm{BSA}(\mathrm{Cal}-$ biochem) was added to defined medium. Medium with serum was the defined medium with $20 \%$ human placental serum added. 

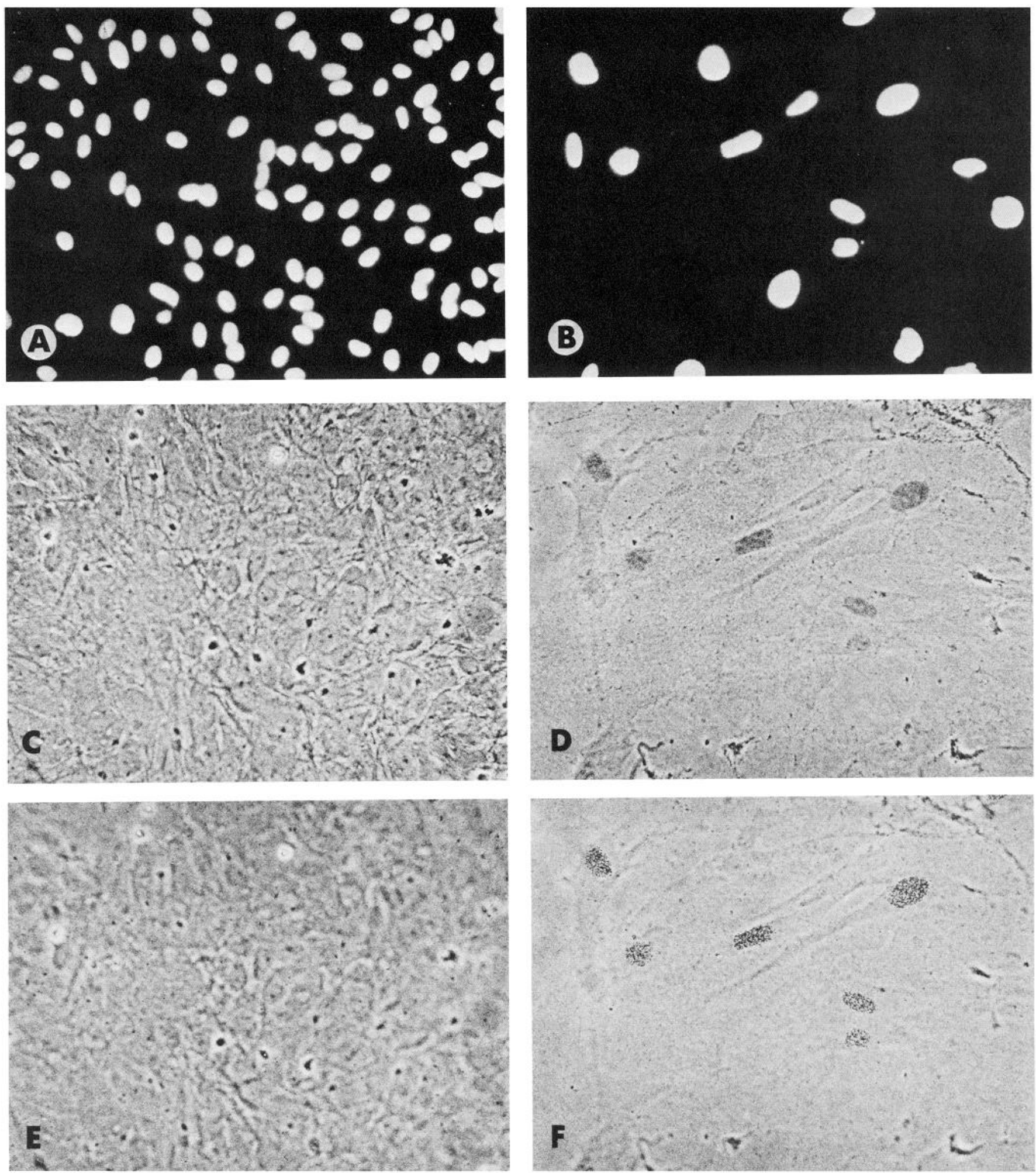

Figure 2. ${ }^{3} \mathrm{H}$-thymidine autoradiography of astrocytes with serum, $18 \mathrm{~d}$ after subculturing. $A, C$, and $E$ are a single field from the central area of the culture. $A$, Cell population is dense, as shown by fluorescent nuclear dye. $C$, Tangle of slender cell processes is visible in phase contrast. $E$, No nuclei have been labeled with silver grains in this area. $B, D$, and $F$ are a single field from the periphery of the culture. $B$, Nuclei are larger and more widely scattered than in the more mature, central area. $D$, Cells appear flat in phase contrast. $F$, Six nuclei of the 17 present are labeled with silver grains. $\times 240$. 

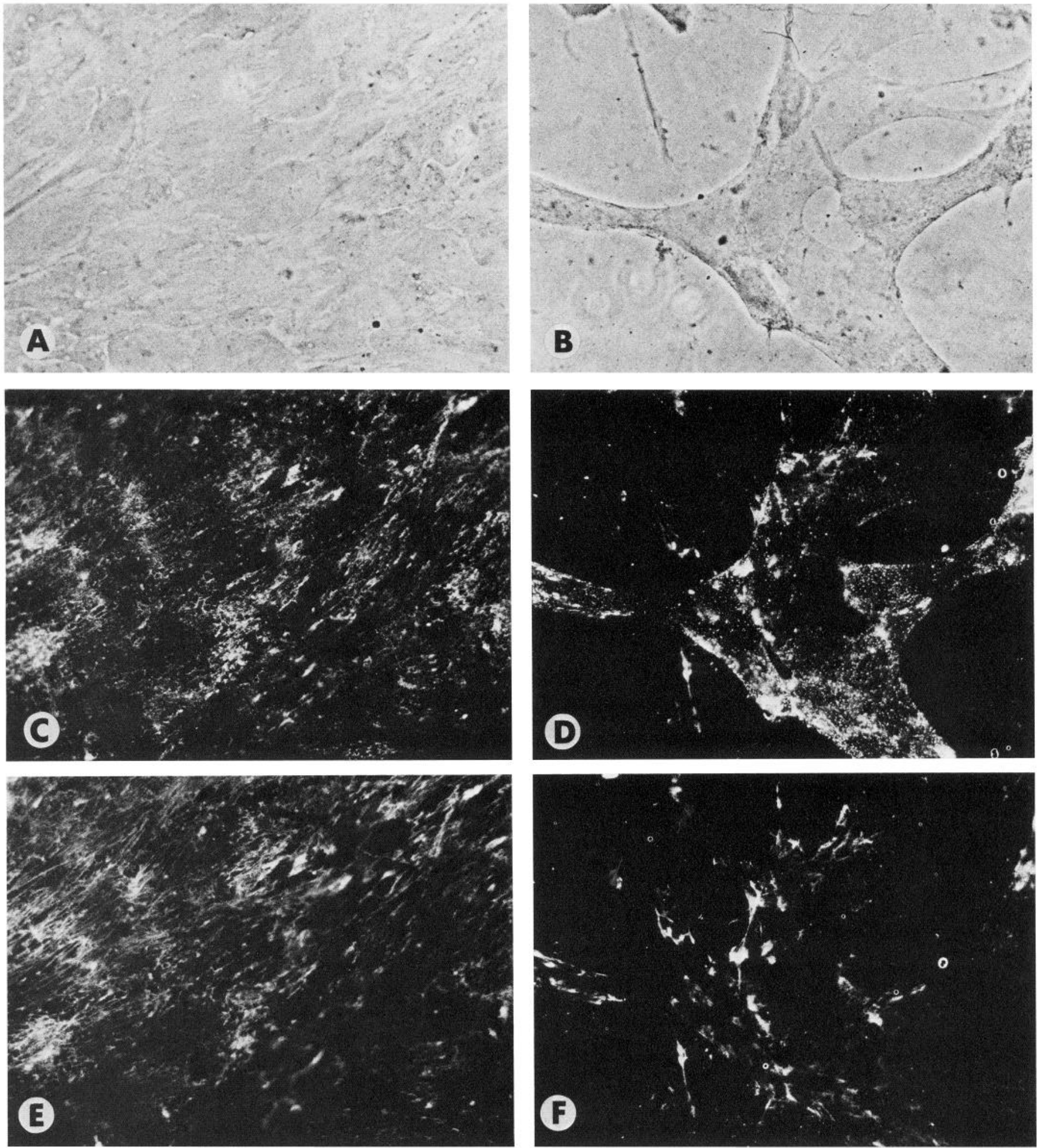

Figure 3. Laminin and HSPG immunostaining of astrocytes with serum, $5 \mathrm{~d}$ after subculturing. $A, C$, and $E$ are the same field, showing $(A)$ a phase-contrast image, $(C)$ anti-laminin, and $(E)$ anti-HSPG distribution on unfixed cells within the monolayer. Anti-laminin and anti-HSPG are colocalized and appear in a fibrillar pattern. $B, D$, and $F$ are a field at the periphery of the astrocyte colony where the population is expanding. On these younger cells, anti-laminin is distributed mostly in a punctate pattern on the cell surface $(D)$, and anti-HSPG immunoreactivity is just beginning to appear $(F) . \times 380$.

Protease inhibitors. In some experiments a protease inhibitor was added to culture medium. The inhibitors employed were the broadspectrum protease inhibitor alpha-2-macroglobulin (Boehringer-Mannheim) at $1 \mathrm{mg} / \mathrm{ml}$ or the plasmin inhibitor aprotinin (Sigma) at 1000 kallikrein inhibitor units/ml.
Dorsal root ganglion explants. Explants of embryonic day 16 rat dorsal root ganglion were cultured with the antimitotic agent fluorodeoxyuridine to obtain pure neuronal cultures without Schwann cells or fibroblasts. Culture medium consisting of Eagle's Minimal Essential Medium (GIBCO) with 10\% human placental serum, $690 \mathrm{mg} \%$ glucose, 


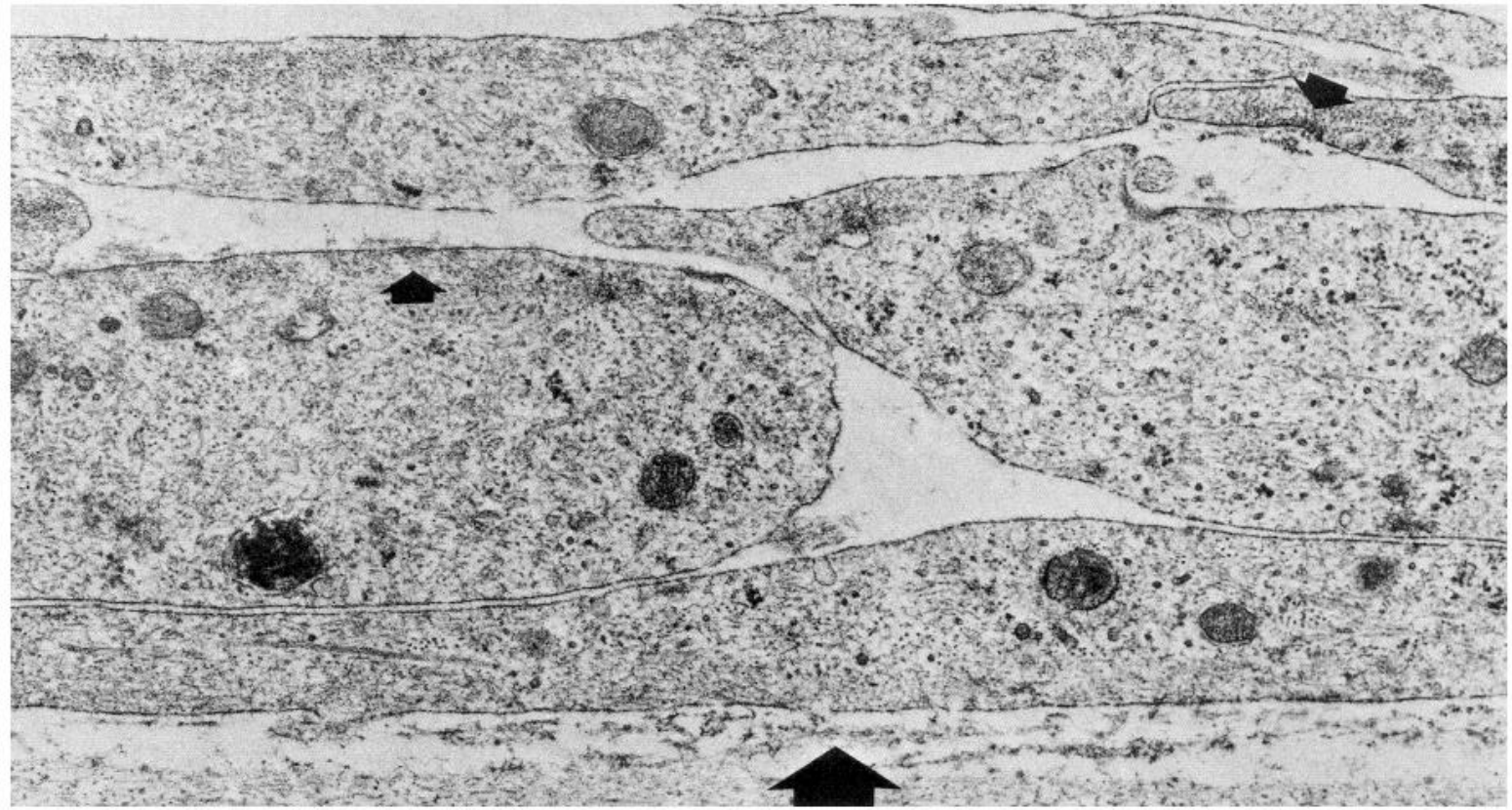

Figure 4. ECM in an $8 \mathrm{~d}$ subculture of astrocytes with serum, demonstrated by EM. A loose, fibrillary matrix has formed near the collagen substratum (large arrow) and in some of the large spaces or channels between the astrocyte processes. Small arrows indicate 2 areas where a basal lamina-like matrix appears to be attached at a membrane thickening. A bundle of glial filaments cut in cross section is prominent near the upper left corner of the picture. Original magnification, 10,000.

and NGF was supplemented with $10^{-5} \mathrm{M}$ fluorodeoxyuridine and $10^{-5}$ M uridine for the first 2 weeks of culture. Thereafter, explants were fed with this supplemented medium for $3 \mathrm{~d}$ each week and without the antimitotic supplement for the other $4 \mathrm{~d}$. Explants were grown in 35 $\mathrm{mm}$ plastic culture dishes coated with rat tail collagen, 6-8 ganglia per dish. Whole or half ganglia, transplanted to astrocyte monolayers after $21 / 2-10$ weeks of antimitotic treatment, grew for $4 \mathrm{~d}$ on astrocyte monolayers before fixation.

Immunocytochemistry. The primary antibodies used for immunocytochemical staining are identified in Table 1 . The control for specific staining was either normal rabbit serum (diluted 1:100; Cooper Biomedical) or application of secondary antibodies alone without primary. Secondary antibodies were fluorescein isothiocyanate-conjugated goat antirabbit immunoglobulin (diluted 1:100; Cappel), rhodamine-conjugated goat anti-mouse immunoglobulin (diluted 1:50; Cappel), or fluoresceinconjugated goat anti-mouse immunoglobulin (diluted 1:100; Antibodies Incorporated). Throughout this study all primary antibodies except antiglial fibrillary acidic protein (anti-GFAP) and anti-neurofilament (RT97) were applied to living cultures before fixation. Cultures were rinsed in L- 15 balanced salt solution with $10 \%$ heat-inactivated horse serum and $0.02 \%$ sodium azide added (buffer), then incubated for $30-60 \mathrm{~min}$ at room temperature in the primary antibody diluted in the same buffer, rinsed, incubated 30-60 min at room temperature in the secondary antibody diluted in buffer, rinsed, fixed in $4 \%$ paraformaldehyde in PBS for 15-30 min, rinsed in $0.1 \mathrm{~m}$ phosphate buffer, and mounted in glycerol or Gelvatol mounting medium. For cell counts the nuclear dye Hoescht 33342 (Sigma) was added to glycerol mounting medium. Anti-GFAP and RT97 immunostaining differed only in that cultures, prior to application of the above protocol, were rinsed in L-15 balanced salt solution and then fixed and permeabilized in $95 \%$ ethanol- $5 \%$ glacial acetic acid for $10-15$ min at $-20^{\circ} \mathrm{C}$.

${ }^{3} \mathrm{H}$-thymidine autoradiography. To quantitate cell proliferation, some cultures were labeled by uptake of ${ }^{3} \mathrm{H}$-thymidine (New England $\mathrm{Nu}$ clear), which was added to culture medium at a concentration of 0.1 $\mu \mathrm{Ci} / \mathrm{ml}$ for $24 \mathrm{hr}$ preceding immunostaining and fixation. The fixed cultures, on glass coverslips, were coated with Kodak NTB2 emulsion, exposed for $4 \mathrm{~d}$, developed, and mounted in glycerol mounting medium with Hoescht nuclear dye 33342.

Electron microscopy. For EM, cultures were fixed in $2 \%$ glutaraldehyde (in $0.046 \mathrm{~m}$ phosphate buffer with $100 \mathrm{~mm}$ sucrose or, when grown in defined medium, in $0.1 \mathrm{M}$ phosphate buffer plus $80 \mathrm{~mm}$ sucrose), postfixed in $2 \% \mathrm{OsO}_{4}$ in $0.1 \mathrm{M}$ phosphate buffer, $\mathrm{pH} 7.4$, dehydrated in ethanol, and embedded in Polybed (Polysciences, Inc.). Thin sections were stained with uranyl acetate and lead citrate.

\section{Results}

Astrocytes grown in either defined medium or serum-containing medium could be labeled with antiserum against GFAP (Fig. 1). Cells in defined medium were process-bearing; those in serum-containing medium were flat and polygonal. To further characterize the cells as astrocytes, parallel cultures were labeled with the monoclonal antibodies Ran 2, a marker for astrocytes (Bartlett et al., 1981; Raff et al., 1984), A2B5, a marker for neurons and for type 2, but not type 1, astrocytes (Raff et al., 1983, 1984), or anti-Thy-1.1, a marker for fibroblasts (Raff et al., 1979), and costained with the nuclear dye Hoescht 33342. Counts of the number of antibody-labeled cells per hundred nuclei revealed the cultures to contain approximately $95 \%$ type 1 astrocytes (positive for anti-GFAP or Ran 2), $2 \%$ fibroblastlike cells (positive for anti-Thy-1.1), and $2 \%$ type 2 astrocytes or small neurons (positive for A2B5). Cells were counted 5 or $6 \mathrm{~d}$ after subculturing, and the composition of the cultures was similar in either defined medium or medium with serum.

More than 400 astrocyte subcultures were plated as single drops of about $5 \mathrm{~mm}$ diameter on collagen-coated coverslips of $22 \mathrm{~mm}$ diameter. After $24 \mathrm{hr}$, subsequent to attachment, the entire coverslip was flooded with medium. In defined medium there was little proliferation; rather, the cell number appeared to diminish as time in culture increased. Thus, at the 5 and 9 d time points used in this study, cultures in defined medium were rather sparsely populated and consisted of small clusters of cell bodies interconnected by long astrocytic processes often aligned parallel to each other. The appearance of cultures in serum-containing medium was quite different. In the presence of serum the astrocytes divided rapidly until they reached confluence; a monolayer was formed within a few days covering 

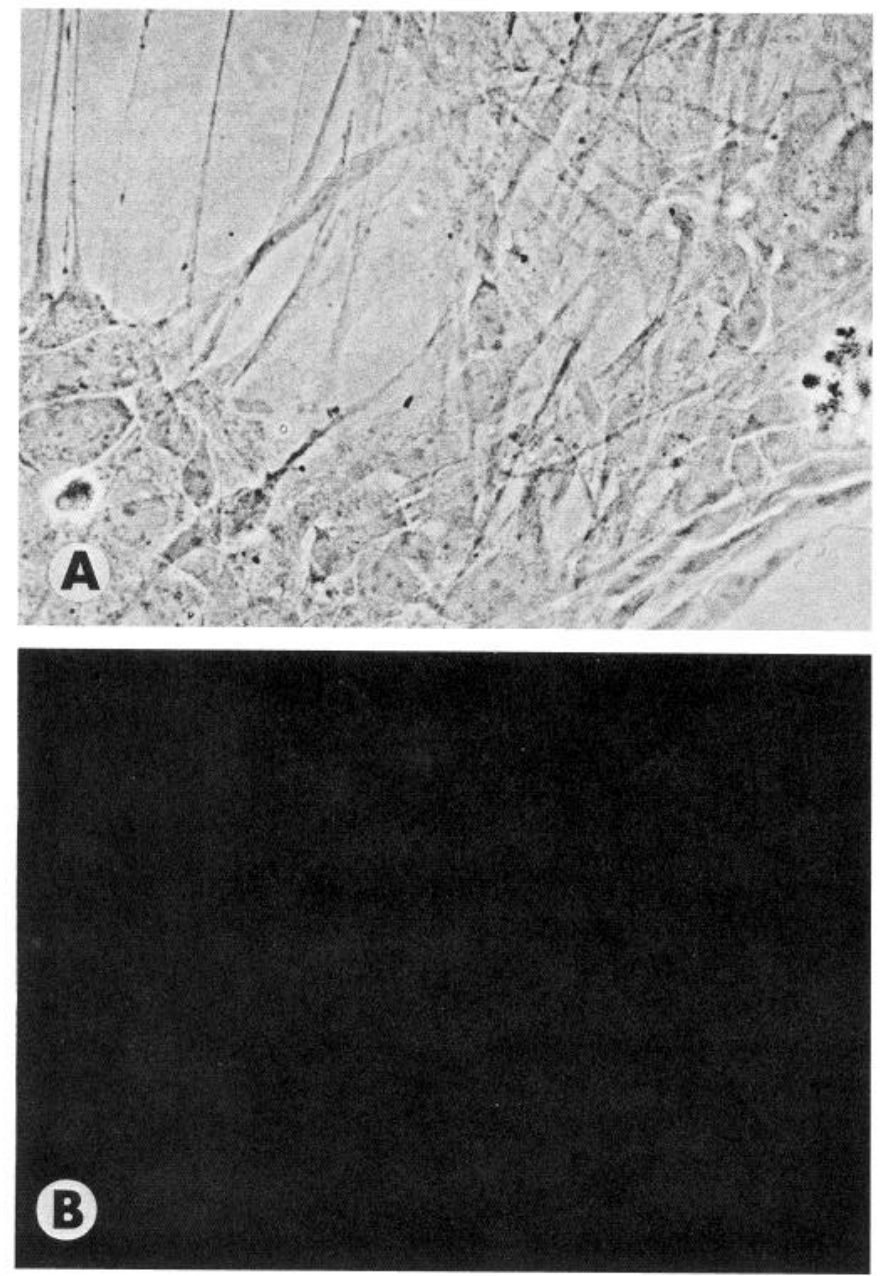

Figure 5. Absence of anti-laminin immunoreactivity in astrocytes subcultured in defined medium for $5 \mathrm{~d}$. $A$, Phase-contrast image; $B$, fluorescent image of the same field. $\times 380$.

the area of the original single drop. Subsequently, proliferative activity appeared to continue mainly around the periphery of that original circle, where cells facing an expanse of unoccupied collagen would not fall under the influence of contact inhibition. The resulting pattern in serum-containing cultures was a central area of quiescent astrocytes surrounded by a ring of proliferative cells. ${ }^{3} \mathrm{H}$-thymidine autoradiography of 6 subcultures maintained with serum for $18 \mathrm{~d}$ resulted in labeling indices of $2 \%$ in the central area and 19\% in peripheral areas of the cultures (Fig. 2).

\section{Deposition of ECM components}

In serum-containing medium at 5 or $9 \mathrm{~d}$ after subculturing, astrocytes could be immunostained with antibodies against HSPG and laminin. The pattern of immunostaining was fibrillar (Fig. 3) and was extracellular, because living cultures were stained without permeabilization. In cultures doubly labeled with both antibodies, using a combination of fluorescein and rhodamine, the 2 immunostaining patterns were almost identical (compare Fig. $3 C$ with $3 E$ ). The exception was that occasionally laminin immunostaining appeared without concomitant HSPG immunostaining. This disparity was most often seen near the periphery of the astrocyte monolayer, where cells had most recently divided; here on the outermost cells, laminin immunostaining
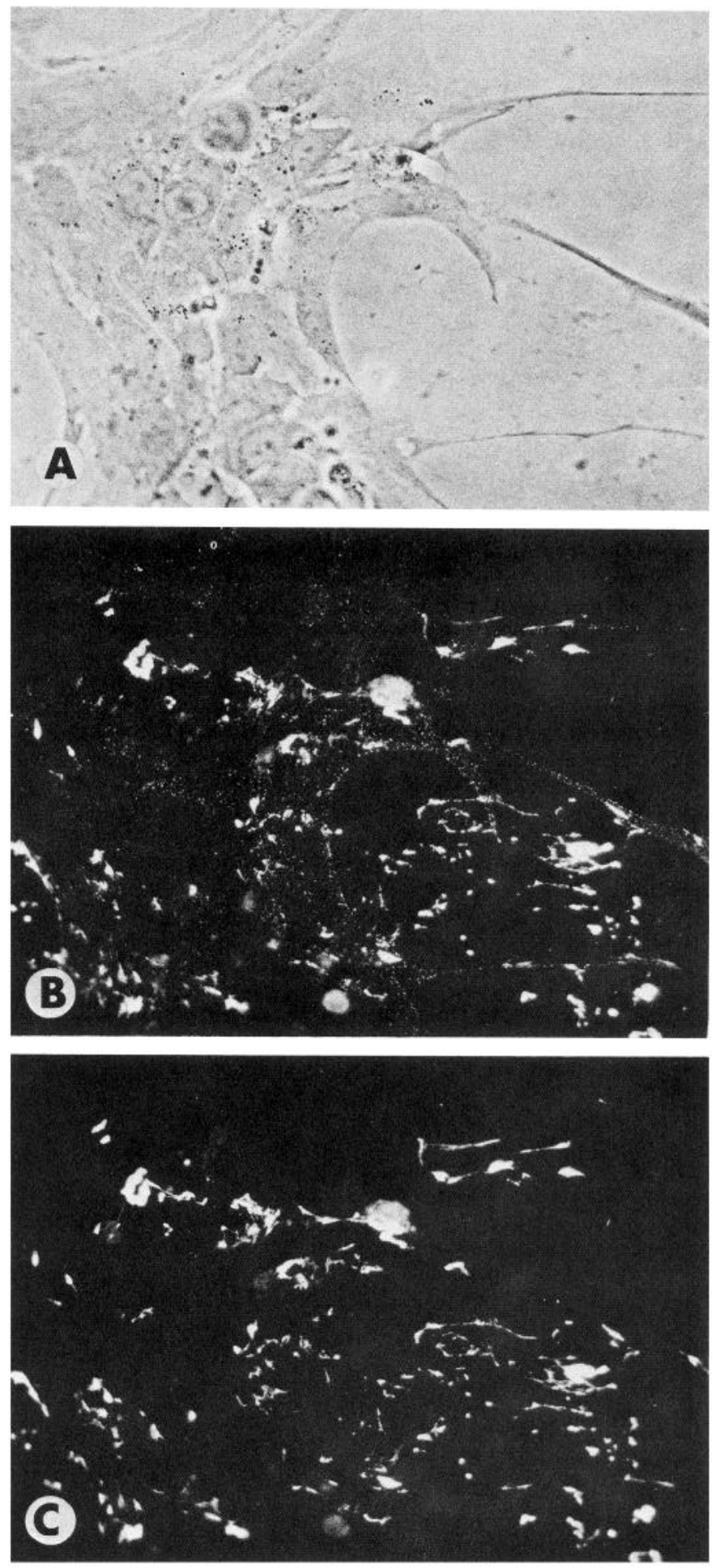

Figure 6. Conversion of subcultures from serum-containing medium $(5 \mathrm{~d})$ to defined medium (for 4 additional days). $A-C$ are the same field. $A$, The process-bearing morphology is visible in phase contrast. $B$, Antilaminin appears in a punctate pattern on the cell surface. Fibrillar antilaminin is reduced compared with that seen in medium with serum (compare with Fig. 3C). Deposits of anti-laminin immunoreactivity are left behind on the culture substratum previously occupied by a confluent monolayer of cells. C, Anti-HSPG distribution matches that of antilaminin except that no punctate immunostaining of the cell surface exists for anti-HSPG. $\times 380$. 

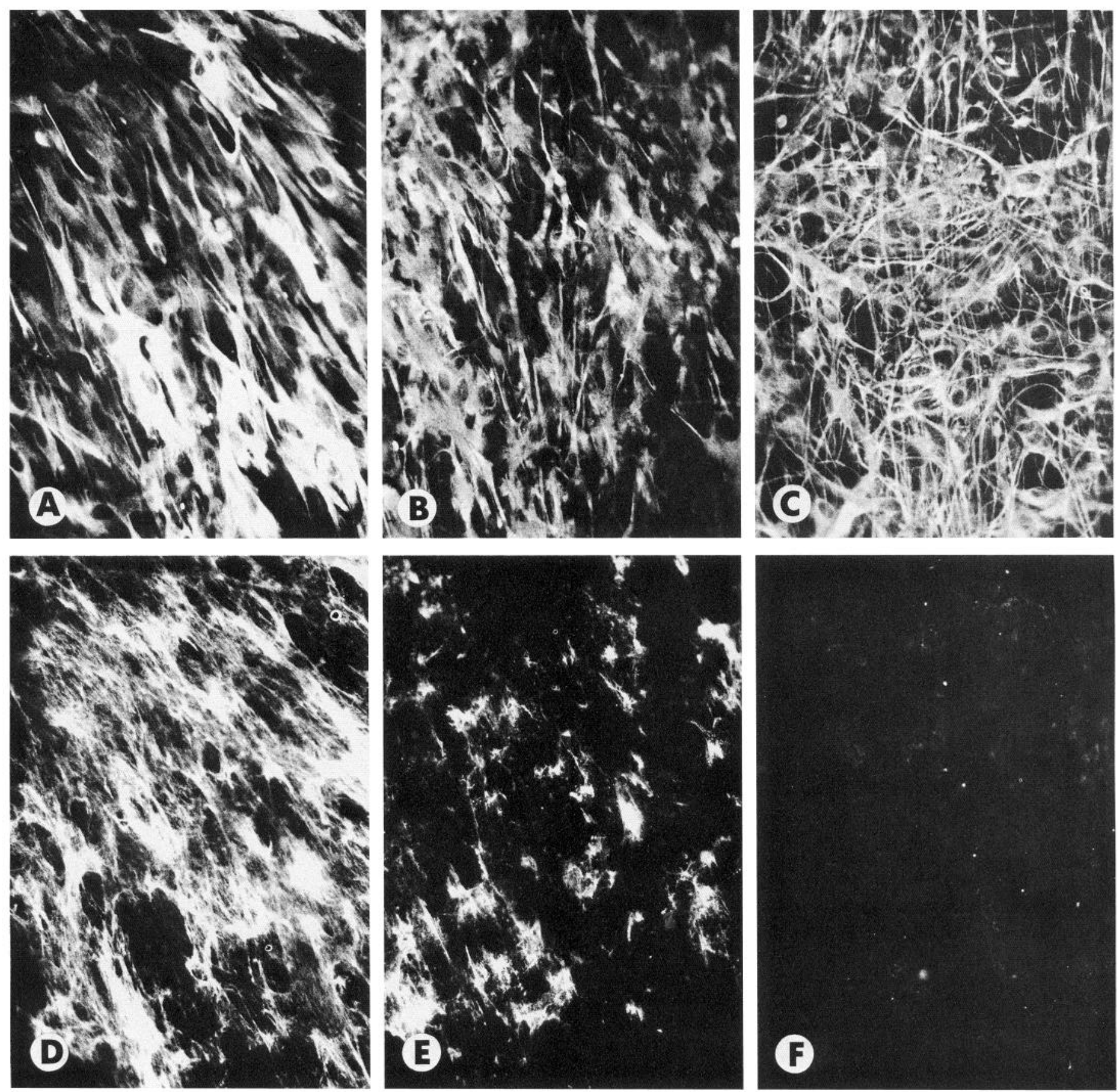

Figure 7. Gradient of differentiation from periphery to center of 33-d-old astrocyte subculture with serum. $A-C$ are anti-GFAP immunofluorescence. $D-F$ are anti-HSPG immunofluorescence. $A$ and $D$, Near the periphery of the colony, astrocytes that have recently divided are flat in shape and heavily labeled with anti-HSPG. $B$ and $E$, Between periphery and center, cell morphology is intermediate between flat and process-bearing. AntiHSPG labeling is moderate. $C$ and $F$, In the central area of the culture, where the proliferative rate is low, older astrocytes are stellate and show little anti-HSPG immunoreactivity. The labeling shown here is the minimum seen; in some differentiated areas the labeling more closely resembles that seen in Figure $9 C . \times 240$.

was punctate rather than fibrillar and covered the cell surface (Fig. 3D). EM confirmed that ECM was assembled in these cultures. Figure 4 shows both a loose, fibrillar matrix lacking attachment to the cell surface but enclosed within intercellular spaces or channels, and small patches of basal lamina attached to the cell surface at membrane thickenings.

When astrocytes were grown in defined medium, neither form of ECM was observed in EM, and fluorescent immunostaining of such cultures was negative for both HSPG and laminin (Fig. 5). Process formation by the cells was greater in defined medium than in serum-containing medium at $5 \mathrm{~d}$ after subculturing.

After a period of $5 \mathrm{~d}$ subculturing with serum, some cultures were converted to defined medium and maintained without serum for a further $4 \mathrm{~d}$. Withdrawal of serum resulted in the morphological change from a confluent monolayer to a population of process-bearing cells (Fig. $6 A$ ). In addition to this change, 

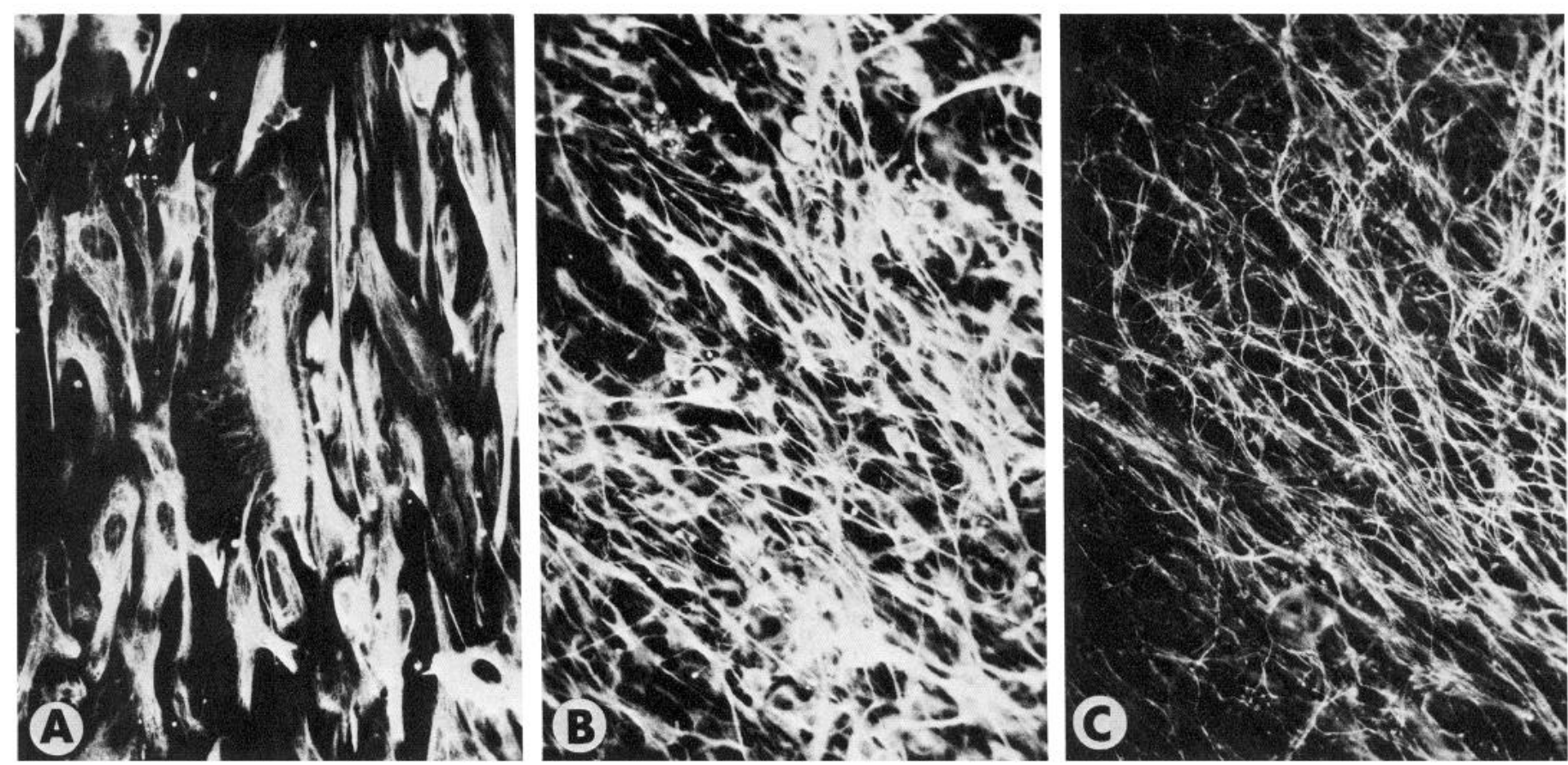

Figure 8. Differentiated morphology of astrocytes in contact with neurites. $A$ and $B$ are anti-GFAP immunofluorescence. $A$, After $5 \mathrm{~d}$ of subculture with serum, most astrocytes are flat or polygonal. $B$, Stellate astrocytes appear in the same culture only in areas where neurites are present. $C$, Neurites in the same field shown in $B$ are demonstrated by anti-neurofilament immunolabeling. $\times 240$.

fibrillar immunostaining for HSPG and laminin was sharply reduced in the converted cultures, while more punctate laminin immunostaining appeared (Fig. 6, B, C; compare to Fig. $3 C$, $E)$. As the cells formed processes and withdrew from previously occupied areas, some ECM that had been deposited on the culture substratum was left behind (most easily seen by comparing Fig. $6 A$ with $6 B$ ). This was the only situation in which deposits of ECM were seen beyond the area directly occupied by the cells.

A similar, correlative change toward a more differentiated morphology with loss of immunostaining for ECM components was noted in older cultures maintained continuously in serum for $30-42 \mathrm{~d}$ after subculturing. In these cultures, a gradient existed between the densely populated central and sparser peripheral areas of the cultures (Fig. 2). Central cells were stellateshaped and showed reduced immunostaininng for HSPG and laminin, while peripheral cells were polygonal, flatter, and showed abundant HSPG and laminin immunostaining (Fig. 7). Because the periphery of these cultures was an open area free of contact inhibition, the astrocytes in this area represented a proliferating, "younger" population.

\section{Interaction of neurites with astrocytes}

Dorsal root ganglion explants, free of non-neuronal cells, were added to astrocyte monolayers $1 \mathrm{~d}$ after subculturing in serumcontaining medium. Neurites from the explants grew onto the layer of astrocytes and could be followed in phase-contrast microscopy or after immunostaining with A2B5 or RT97 antibodies (Table 1). Morphological changes in astrocytes occurred in the vicinity of the neurites, as shown in Figure 8. Flat or polygonal astrocytes were typical in cultures maintained for 5 $\mathrm{d}$ with serum, but astrocytes in contact with neurites were stellate in these cultures. Neurite growth on the astrocyte surfaces dramatically reduced immunostaining of astrocytes for HSPG and laminin (Figs. 9, 10). The effect was localized and confined to the vicinity of the neurites, although its precise boundaries could not be determined because of the patchy nature of the immunostaining. Nevertheless, the marked reduction in immunostaining in the area of the neurites was clearly different in magnitude from any unevenness seen in other areas of these cultures (Fig. 10). In EM (Fig. 11), neurites were seen usually in contact with astrocyte surfaces or with other neurites. In areas with neurites, little of the fibrillar matrix or basal lamina appeared. Instead, the ECM consisted of a thin, wispy material (compare Fig. 11 with Fig. 4, both taken from different areas of the same culture).

Dorsal root ganglion explants were placed on ten 29-d-old subcultures of astrocytes with serum. Relatively little HSPG or laminin immunostaining was present in the central areas of these cultures where the neurons were placed, yet neurites grew well on the astrocyte surface, with the neurite length observed after $4 \mathrm{~d}$ growth not significantly different from that seen on freshly plated monolayers (Table 2).

Neuronal explants were also added to astrocytes subcultured in defined medium. In this condition, neurites were found in contact with astrocyte surfaces rather than on the unoccupied collagen substratum between the sparse clusters of cells (Fig. 12). Astrocyte processes interacted with neuritic bundles, partially enclosing some fascicles (seen by EM in Fig. 13). The pattern of astrocyte growth in defined medium, i.e., small, randomly distributed clusters of cell bodies interconnected by a network of long processes, was the same in the presence or absence of neurites.

\section{Addition of protease inhibitors to culture medium}

A sharp reduction in immunostaining of ECM components occurred in short-term cultures to which neurons were added. In order to determine whether the reduction in ECM immuno- 

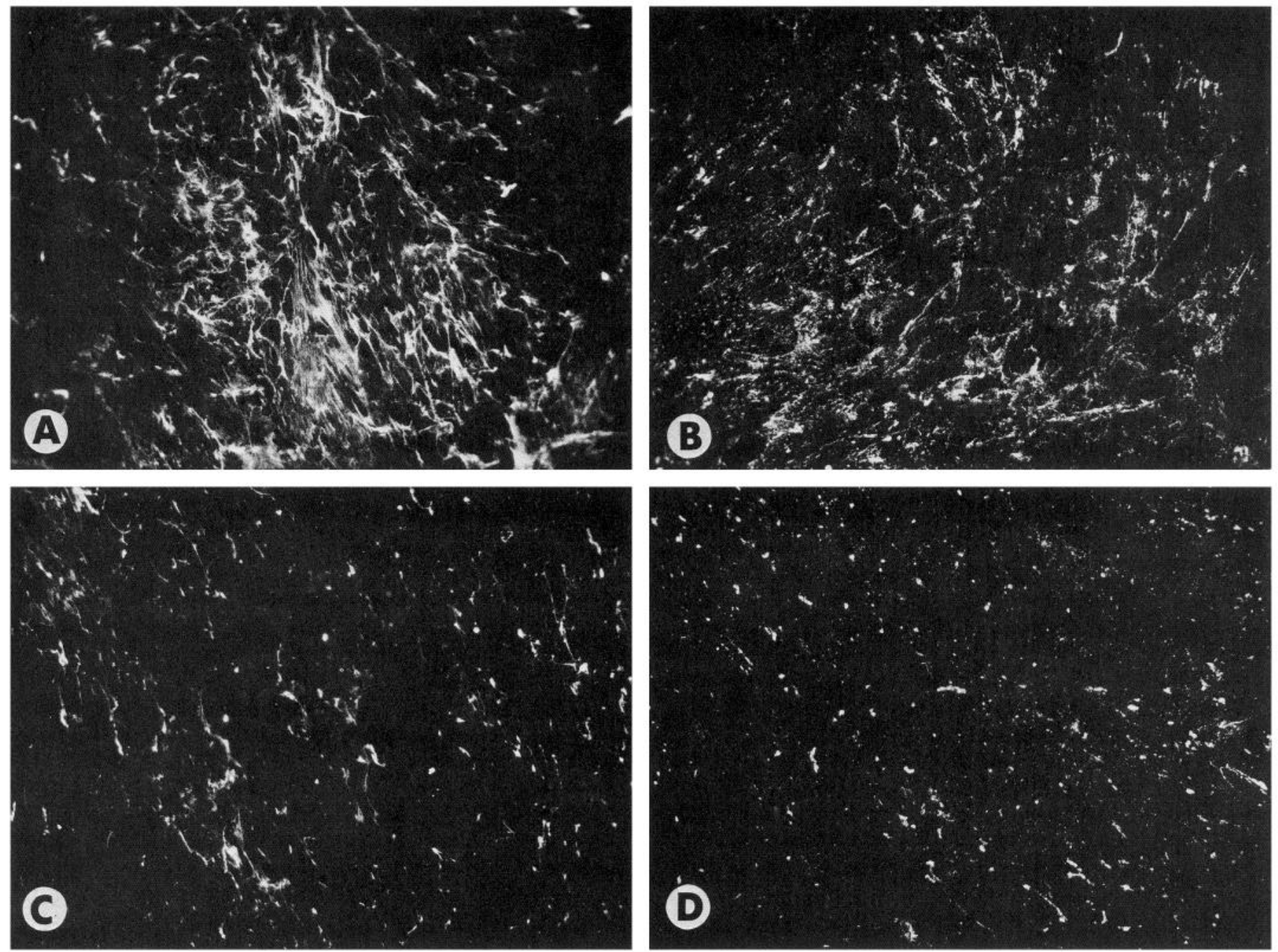

Figure 9. Reduction of anti-HSPG and anti-laminin labeling where astrocytes are contacted by neurites. $A$ and $C$ are anti-HSPG immunofluorescence. $B$ and $D$ are anti-laminin immunofluorescence. $A$ and $B$, A fibrillar ECM is present in $5 \mathrm{~d}$ astrocyte subcultures with serum. $C$ and $D$, In the same cultures, immunolabeling of ECM is greatly reduced in areas where neurites have grown. Neurites from dorsal root ganglion explants grown for $4 \mathrm{~d}$ on the astrocyte monolayers cover the entire field shown in $C$ and $D . \times 240$.

Table 1. Antibodies used for immunofluorescent labeling

\begin{tabular}{|c|c|c|c|}
\hline Antigen & Antibody (dilution) & Source & Ref. \\
\hline \multirow[t]{2}{*}{ Basal lamina HSPG } & B3 monoclonal $(1: 100)$ & Cornbrooks & Eldridge et al., 1986 \\
\hline & anti-HSPG rabbit serum $(1: 50)$ & Hassell & Hassell et al., 1985 \\
\hline \multirow[t]{2}{*}{ Laminin } & $\begin{array}{l}\text { anti-laminin } 900+\text { rabbit serum (1: } \\
100)\end{array}$ & Timpl & Eldridge et al., 1987 \\
\hline & anti-laminin rabbit serum $(1: 100)$ & Gatchalian and Sanes & \\
\hline $\begin{array}{l}\text { Cell surface of neurons and type } \\
2 \text { astrocytes }\end{array}$ & A2B5 monoclonal (1:50) & $\begin{array}{l}\text { American Type Culture } \\
\text { Collection }\end{array}$ & $\begin{array}{l}\text { Raff et al., 1983; Raff et al., } \\
\quad 1984\end{array}$ \\
\hline $\begin{array}{l}\text { Cell surface gangliosides of } \\
\text { astrocytes }\end{array}$ & $\begin{array}{l}\text { Ran } 2 \text { monoclonal (undiluted culture } \\
\text { supernatant) }\end{array}$ & $\begin{array}{l}\text { American Type Culture } \\
\text { Collection }\end{array}$ & $\begin{array}{l}\text { Bartlett et al., 1981; Raff et al., } \\
1984\end{array}$ \\
\hline $\begin{array}{l}\text { Cell surface gangliosides of } \\
\text { fibroblasts }\end{array}$ & $\begin{array}{l}\text { anti-Thyl. } 1 \text { monoclonal (undiluted } \\
\text { culture supernatant) }\end{array}$ & $\begin{array}{l}\text { American Type Culture } \\
\text { Collection }\end{array}$ & Raff et al., 1979 \\
\hline Astrocyte intermediate filaments & anti-GFAP rabbit serum $(1: 200)$ & Eng & Bignami et al., 1972 \\
\hline Neurofilaments & RT97 monoclonal (1:100) & Wood & Wood and Anderton, 1981 \\
\hline
\end{tabular}




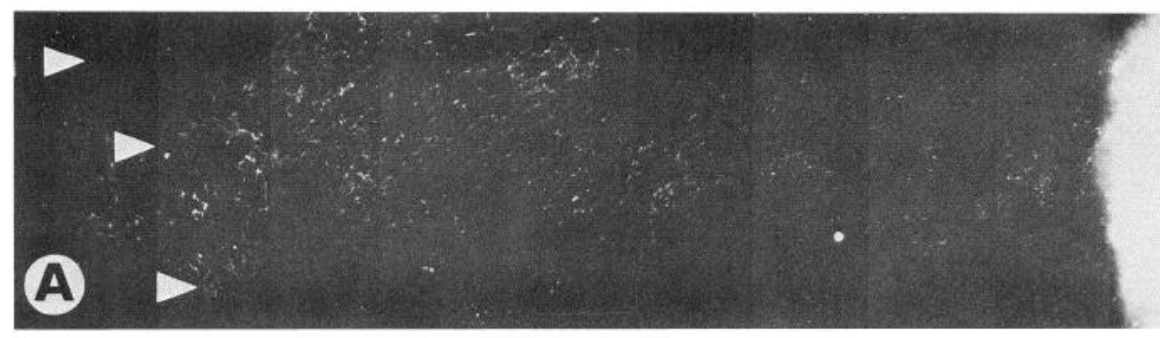

\section{DRG}
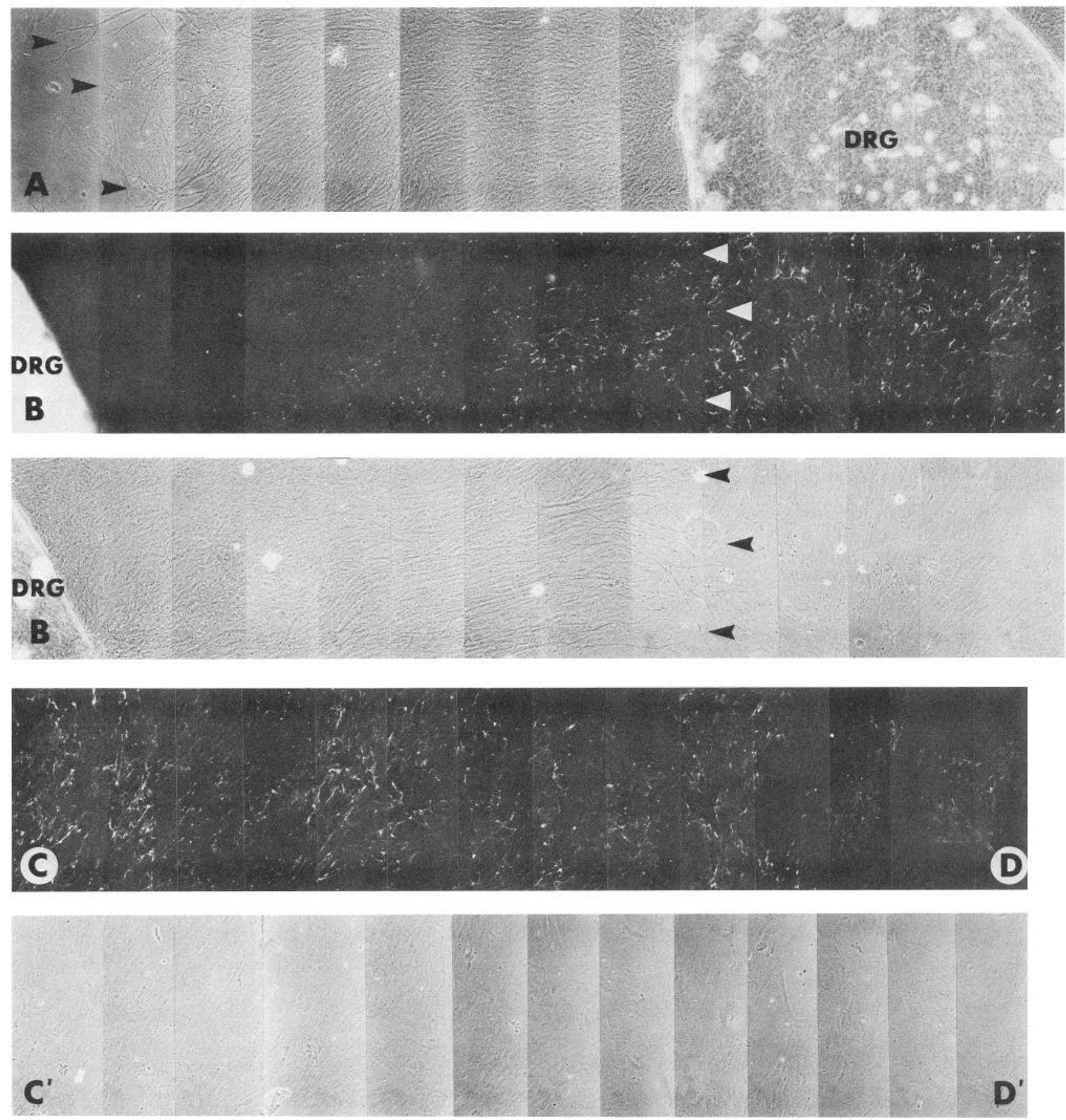

Figure 10. An explant of dorsal root ganglion $(D R G)$ neurons grown on an astrocyte monolayer for $4 \mathrm{~d}$. Astrocytes were subcultured for $5 \mathrm{~d}$ with serum; the neurons, along with the protease inhibitor alpha-2-macroglobulin, were added $1 \mathrm{~d}$ after subculturing. This montage, beginning on the upper left at $A$ (anti-HSPG immunofluorescence) and $A^{\prime}$ (matching phase contrast) and ending on the lower right at $D$ and $D^{\prime}$, covers the entire diameter of the astrocyte monolayer. Neurites have grown from the ganglion to the extent indicated by arrowheads. Clearly, anti-HSPG immunostaining is diminished in the area beneath the neurites. The effect is localized; bright, fibrillar immunostaining is present to the right of the arrowheads in row $B$ and throughout row $C$, where neurites are absent. $\times 80$. 


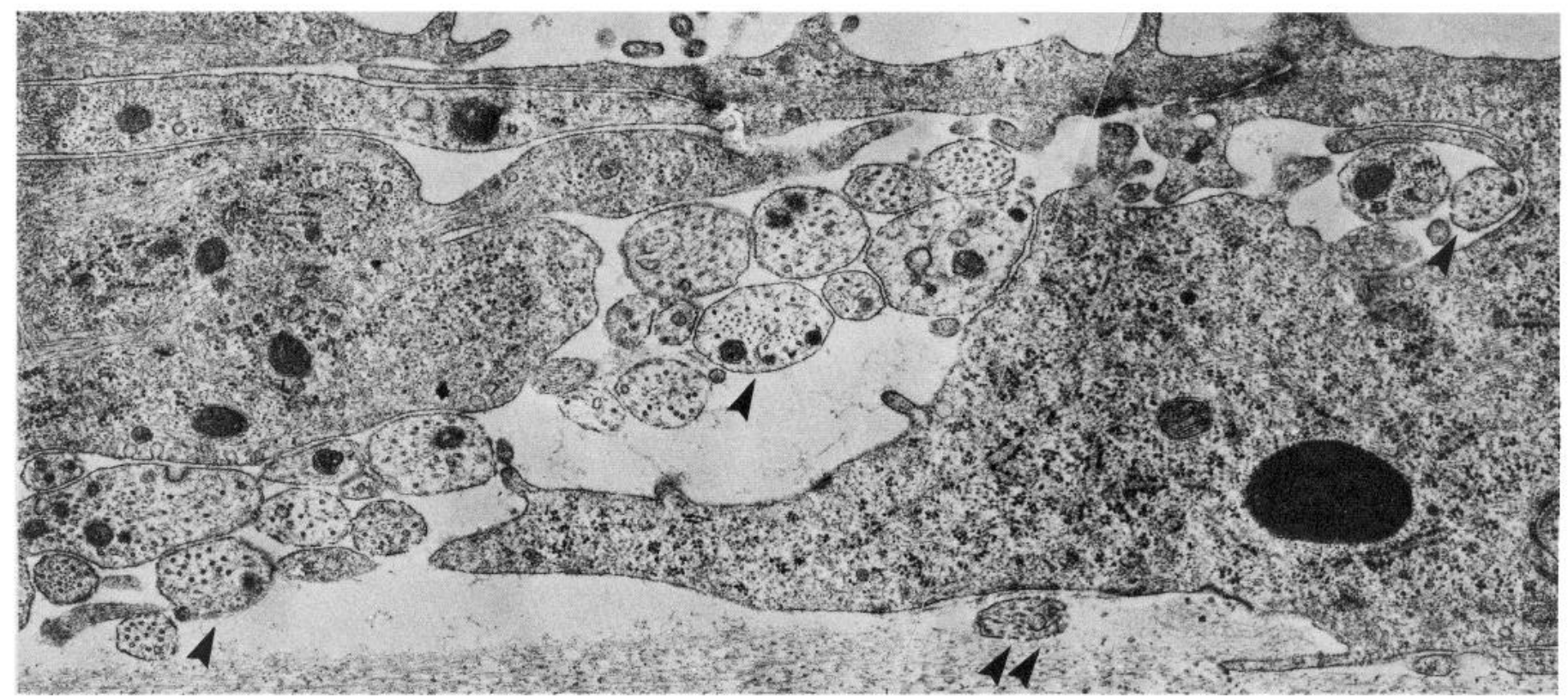

Figure 11. Neurites growing among astrocyte processes. Cross-sectioned neurites (some marked by arrowheads), identifiable by their arrays of microtubules, contact each other or the surfaces of irregularly shaped astrocytic profiles. Only one cellular process which may be a neurite (double arrowheads) contacts ECM of a basal lamina or fibrillar type. In the area where most neurites are found, only a thin, wispy ECM is seen. This is a reduction compared to the ECM shown in Figure 4, which was taken from a neurite-free region of this same culture. The astrocytes were subcultured for $1 \mathrm{~d}$, and neurons were then added; astrocytes and neurons were maintained for an additional $7 \mathrm{~d}$ with serum. Original magnification, 10,000 .

staining might be mediated by a protease, protease inhibitor was added to some of these cultures. Neither of the 2 protease inhibitors tested, alpha-2-macroglobulin at $1 \mathrm{mg} / \mathrm{ml}$ or aprotinin at 1000 kallikrein units/ml, prevented the loss of HSPG and laminin immunostaining associated with neurite growth on the astrocytes. This experiment was done in 2 ways. First, alpha2-macroglobulin was added to serum-containing medium, and this was fed to cultures during the $4 \mathrm{~d}$ period of dorsal root ganglion neurite growth on the astrocyte layer. In the presence of serum, alpha-2-macroglobulin did not prevent the neuriteassociated loss of HSPG and laminin immunostaining (Fig. 10). Therefore, to control for the possibility that serum might interfere with the activity of the protease inhibitor, the experiment was repeated with either alpha-2-macroglobulin or aprotinin (at the concentrations given above) added to defined medium. After $5 \mathrm{~d}$ of growth in serum-containing medium, the astrocyte subcultures were converted to defined medium with protease inhibitor for the $4 \mathrm{~d}$ period of neurite growth. These cultures maintained some HSPG and laminin immunoreactivity in neurite-free areas, yet reduction of HSPG immunostaining still occurred in areas of neurite growth. This result was obtained in 2 experiments with alpha-2-macroglobulin and in one experiment with aprotinin.

\section{Discussion}

Our immunocytochemical studies on living cells have shown that astrocytes in culture accumulated both HSPG and laminin on their surfaces. These components were for the most part colocalized and appeared to be assembled into an irregular ECM; the presence of an ECM was confirmed by EM observation. HSPG immunostaining occurred exclusively in a fibrillar pattern. Laminin immunostaining was usually fibrillar and colocalized with HSPG, except in the most recently generated, peripheral regions of the cultures, where laminin immunostaining was in a punctate pattern on the cell surface and preceded the appearance of HSPG immunoreactivity. When HSPG-immunoreactive fibrils subsequently appeared, the punctate pattern of laminin immunostaining gave way to the fibrillar pattern of the ECM, suggesting that HSPG production signaled a reorganization of laminin distribution by the cells.

HSPG and laminin deposition were reduced with increasing morphological differentiation of the astrocytes. Immunostaining for both molecules was intense under conditions in which astrocytes were flat in shape and rapidly growing. Such conditions required serum in the culture medium. This result is in agreement with the earlier studies of Liesi et al. (1983) and Selak et

Table 2. Neurite length after 4 days on astrocyte monolayers

\begin{tabular}{lllll} 
Monolayers & Immunostaining & $\begin{array}{l}\text { Mean }( \pm \text { SEM) length } \\
(\mathrm{mm})\end{array}$ & $\begin{array}{l}\mathrm{Range}^{b} \\
(\mathrm{~mm})\end{array}$ & $n$ \\
\hline Subcultured 1 d, with serum, confluent (3 experiments) & laminin $^{+}, \mathrm{HSPG}^{+}$ & $2.2 \pm 0.1$ & $2.0-2.5$ & 13 \\
Subcultured 29 d, with serum, confluent (2 experiments) & laminin $^{-(+)}, \mathrm{HSPG}^{-(+)}$ & $1.8 \pm 0.3$ & $1.0-2.6$ & 7 \\
Subcultured 1 d, serum-free, sparse (3 experiments) & laminin $^{-}$, HSPG $^{-}$ & Present, not measured & & 8
\end{tabular}

a For each dorsal root ganglion explant, the measurement taken was the length of the longest single bundle of neurites.
${ }^{b}$ Lengths of neurites were compared using the Mann-Whitney test, and no significant difference was found at $p=0.05$. 

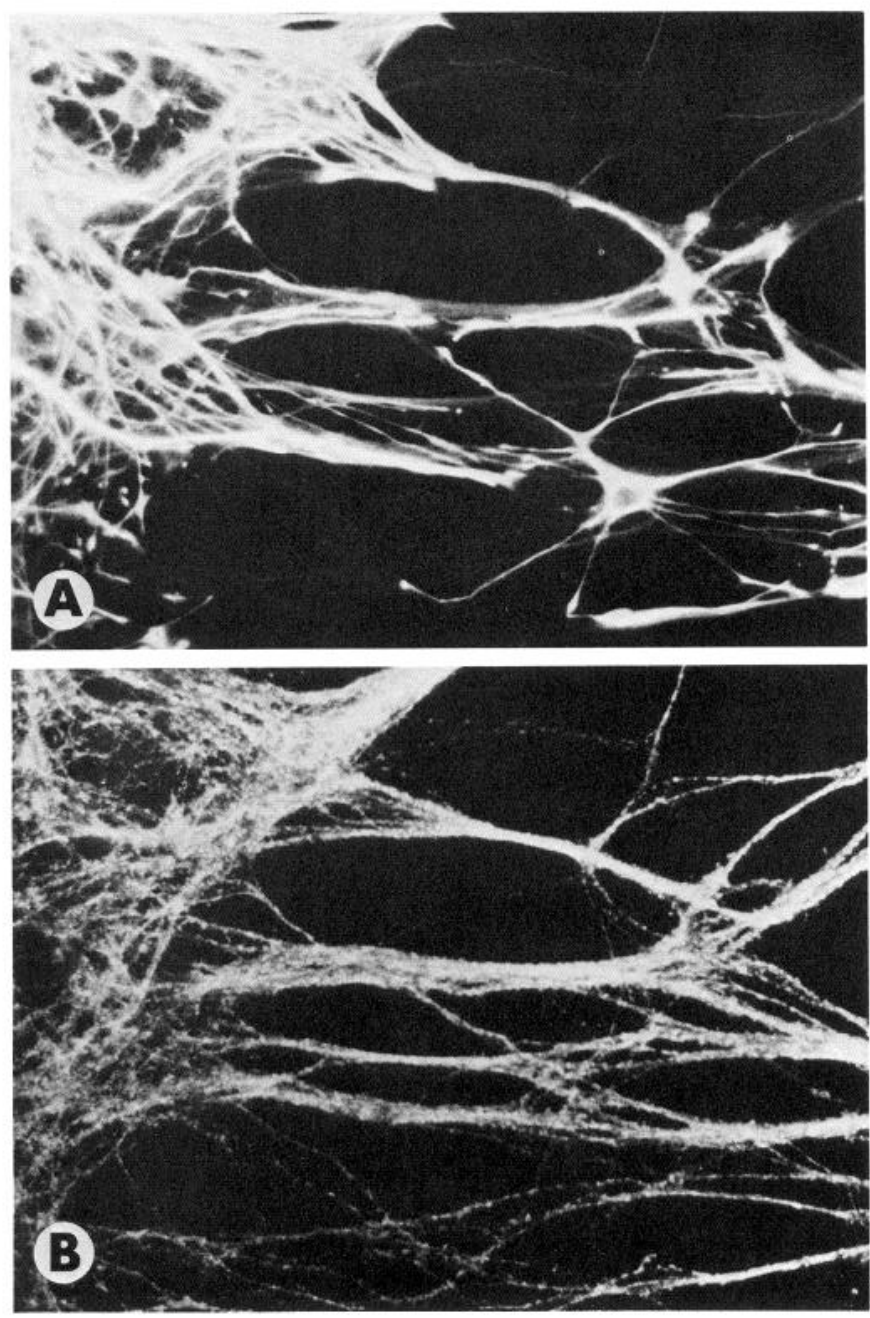

Figure 12. Neurites codistribute with astrocyte processes in defined medium. $A$ and $B$ are the same field. $A$, Anti-GFAP labels astrocytes, which grow sparsely and in clusters in defined medium. $B$, A2B 5 antibody labels neurites, which grow in contact with the astrocytes rather than on the collagen substratum. Astrocyte subcultures grew for $1 \mathrm{~d}$ before addition of neurons; astrocytes and neurons were then maintained for 4 more days in defined medium. $\times 240$.

al. (1985) showing laminin production by cultured astrocytes that were flat and grown in the presence of serum. Conversion of cultured astrocytes from flat to stellate form upon withdrawal of serum is well documented (e.g., Moonen et al., 1975, 1976; Fan and Uzman, 1977; Duffy, 1982; Morrison and de Vellis, 1983; Michler-Stuke et al., 1984). In our cultures in defined medium, stellate astrocytes formed sparsely populated cultures that exhibited no HSPG or laminin immunoreactivity, suggesting that the stellate form represented an advanced state of differentiation that precluded their production of ECM. Alternatively, some necessary ingredient or cofactor for matrix production might have been missing from defined medium (for example, Schwann cells require vitamin $\mathrm{C}$ for assembly of basal lamina: Carey and Todd, 1987; Eldridge et al., 1987). In support of the first view, astrocytes maintained in long-term culture (subcultured 30-42 d in the continued presence of serum) eventually lost much of their HSPG and laminin immunostaining as they differentiated to a stellate form. Liesi et al. (1983) also described cessation of laminin production by astrocytes with increasing time in culture as shown by the disappearance of intracellular immunostaining for laminin. In their studies, in contrast to our results, extracellular laminin fibrils were preserved in older cultures. Morphological differentiation of the astrocytes in $30 \mathrm{~d}$ cultures was reported by Liesi et al. to be much less pronounced, however, than that seen in our cultures. (Fetal bovine serum was used in their cultures, human placental serum in ours.) An interesting parallel with the loss of HSPG and laminin immunostaining in culture is the disappearance in vivo of early laminin immunoreactivity of astrocytes as the rat CNS matures (Liesi, 1985a).

Four other ECM constituents have been demonstrated in astrocytes. Chondroitin sulfate proteoglycan has been immunocytochemically visualized extracellularly in developing rat brain but becomes restricted to an intracellular location within astrocytes and neurons in adulthood (Aquino et al., 1984a, b). Hyaluronectin appears to form an ECM around white matter astrocytes and subependymal and other glia, with additional, wider distribution embryonically (Bignami and Delpech, 1985; Bignami and Dahl, 1986). Cytotactin, a protein mediating glianeuron adhesion in vitro, is associated with glia of the chick cerebellum during development and in culture (Grumet et al., 1985). Fibronectin immunoreactivity has been shown to be limited spatially and temporally in embryonic mouse brain, appearing first in the preplate and then in the subplate and marginal zone of cortex around the time of arrival of afferent axons in this region (Stewart and Pearlman, 1987). Earlier work with fibronectin immunostaining led to differing conclusions about whether fibronectin appeared in the CNS (Schachner et al., 1978; Minier et al., 1981; Hatten et al., 1982; Jones et al., 1982). In tissue culture studies, astrocytes have been shown to secrete fibronectin without depositing it into an ECM (Price and Hynes, 1985). Other researchers found fibronectin immunoreactivity both intracellularly and in a fibrillar form of ECM in astrocyte cultures, depending upon the brain region from which the cultures were taken and the age of the cells (Liesi et al., 1986). These data in sum indicate a changing role for ECM components during development of the CNS.

In our cultures the growth of dorsal root ganglion neurites on astrocytes caused a sharply localized reduction of HSPG and laminin immunostaining in areas of direct contact between the 2 cell types. This may again represent a correlation between down-regulation of ECM and development of process-bearing morphology by the astrocytes because it has previously been shown that neuronal contact stimulates a change in astrocytic shape from flat to process-bearing, along with a decrease in astrocytic proliferation (Sobue and Pleasure, 1984; Hatten and Mason, 1986; Hatten, 1987). A similar change in shape has been noted in our preparations also. The loss of HSPG and laminin immunostaining from astrocyte surfaces in contact with neurites was not prevented by protease inhibitors. Nevertheless, this result does not rule out the possibility that the reduction in ECM is caused by release of a protease from the growing tips of neurites, as has been suggested in other culture systems (Krystosek and Seeds, 1981, 1986; Pittman, 1985). Neither of the inhibitors tested, alpha-2-macroglobulin nor aprotinin, universally blocks all proteases, and inhibitors may not have access to cell surface proteases in close cell contacts (Fairbairn et al., 1985). On the other hand, target cells may themselves remodel their ECM under the stimulus of neuritic contact. Such was the conclusion reached by Anderson (1986) because ECM was temporarily lost 
Figure 13. Neurites growing among astrocyte processes in defined medium. Irregularly shaped astrocyte processes partially enclose a bundle of cross-sectioned neurites (identifiable by their arrays of microtubules). The collagen substratum is visible in the lower-left corner. The astrocytes were subcultured for $1 \mathrm{~d}$; then, neurons were added, and astrocytes and neurons were maintained for an additional $7 \mathrm{~d}$ in defined medium. Original magnification, 8000 .

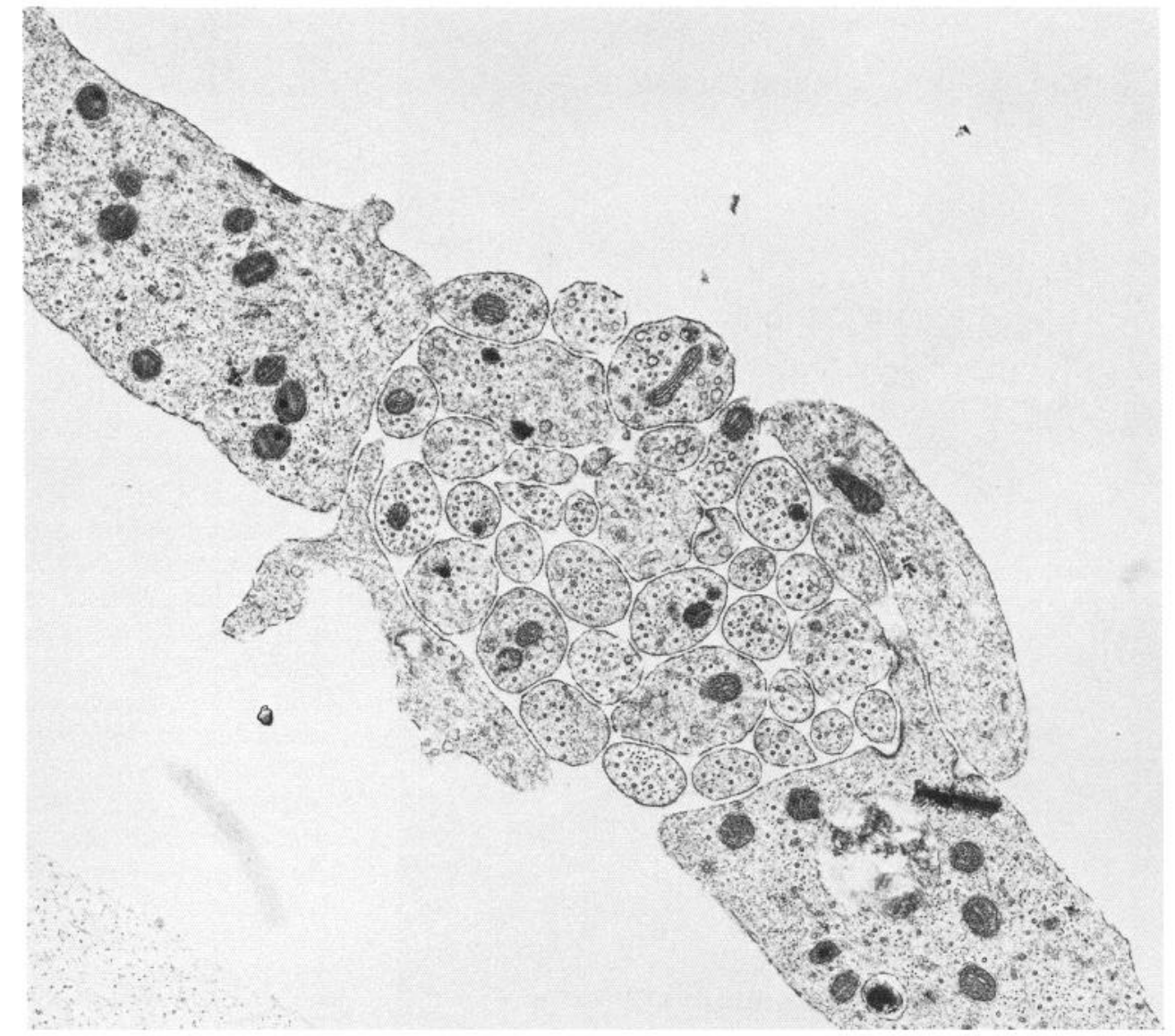

from muscle cells, but not from epithelial cells, contacted by neurites in culture.

The influence of neuronal contact on astrocytes is strikingly different from its influence on Schwann cells. In the PNS, contact with neurites up-regulates first Schwann cell proliferation and then deposition of ECM (Bunge et al., 1983; Cornbrooks et al., 1983). Our results suggest that in the CNS neurite contact may have the opposite effect: astrocytes in contact with neurites lose immunostaining for ECM components, and their rate of proliferation declines (Sobue and Pleasure, 1984; Hatten and Mason, 1986; Hatten, 1987). The common effect in these 2 systems is that in each case interaction with neurites drives glia toward expression of differentiated properties.

Although ECM from various cell types is known to promote neurite outgrowth (Ide et al., 1983; Hall, 1986; Kuffler, 1986; Tomaselli et al., 1986; Ard et al., 1987; Davis et al., 1987), in the present work we have shown that laminin and HSPG were not required for interaction between sensory neurites and astrocyte surfaces. In defined medium, in which astrocytes produced no immunostainable HSPG or laminin, neurites were found in contact with astrocytes rather than on the rat tail collagen substratum. Neurites also grew on astrocyte monolayers that had been subcultured for more than 4 weeks before neurons were added and thus retained relatively little HSPG or laminin. These findings are in agreement with previous studies indicating that neurite growth on astrocyte surfaces did not depend on the capacity of neurites to respond to laminin (Cohen et al., 1986) and was not blocked by laminin-fibronectin receptor antibodies that blocked growth on ECM (Tomaselli et al., 1986).

Recently it has been suggested that immature, but not mature, astrocytes support axonal growth (Smith et al., 1986). Comparisons are difficult because of the lack of a clear, widely applicable definition of astrocyte maturity. The work of Smith et al. (1986) has taken an interesting and successful approach in transplanting embryonic astrocytes to adult mouse brains. However, attempts to compare embryonic, transplanted astrocytes with mature host astrocytes have suffered from the absence of a demonstration that the mature host cells in question were a pure population of astrocytes. Contaminating fibroblasts or other cell types could have affected the results. Currently, data are accumulating that catalog differences between immature and morphologically differentiated astrocytes, e.g., proliferation slows concomitant with the change from flat to stellate shape (Lindsay et al., 1982; Sobue and Pleasure, 1984; Hatten and Mason, 1986; Hatten, 1987); synthesis of S-100 protein increases (Fan and Uzman, 1977; Lim et al., 1977; Weibel et al., 1985); prostaglandin $\mathrm{D}_{2}$ production increases (Seregi et al., 1987); astrocytes acquire the ability to take up GABA (Levi et al., 1983); and expression of $\beta$-adrenergic receptors changes (Trimmer and McCarthy, 1986; Voisin et al., 1987). The present results, by expanding this catalog of differentiated characteristics, make it possible to begin comparing immature and mature astrocytes in tissue culture, where the number of interacting cell types may be carefully controlled. 


\section{References}

Aguayo, A., S. David, P. Richardson, and G. Bray (1982) Axonal elongation in peripheral and central nervous system transplants. Adv. Cell Neurobiol. 3: 215-234.

Anderson, M. J. (1986) Nerve-induced remodeling of muscle basal lamina during synaptogenesis. J. Cell Biol. 102: 863-877.

Aquino, D. A., R. U. Margolis, and R. K. Margolis (1984a) Immunocytochemical localization of a chondroitin sulfate proteoglycan in nervous tissue. I. Adult brain, retina, and peripheral nerve. J. Cell Biol. 99: 1117-1129.

Aquino, D. A., R. U. Margolis, and R. K. Margolis (1984b) Immunocytochemical localization of a chondroitin sulfate proteoglycan in nervous tissue. II. Studies in developing brain. J. Cell Biol. 99: 11301139.

Ard, M. D., R. P. Bunge, and M. B. Bunge (1987) A comparison of the Schwann cell surface and Schwann cell extracellular matrix as promoters of neurite growth. J. Neurocytol. 16: 539-555.

Baron-Van Evercooren, A., H. K. Kleinman, S. Ohno, P. Marangos, J. P. Schwartz, and M. E. Dubois-Dalcq (1982) Nerve growth factor, laminin, and fibronectin promote neurite growth in human fetal sensory ganglia cultures. J. Neurosci. Res. 8: 179-193.

Bartlett, P. F., M. D. Noble, R. M. Pruss, M. C. Raff, S. Rattray, and C. A. Williams (1981) Rat neural antigen-2 (Ran-2): A cell surface antigen on astrocytes, ependymal cells, Muller cells and leptomeninges defined by a monoclonal antibody. Brain Res. 204: 339-351.

Bignami, A., and D. Dahl (1986) Brain-specific hyaluronate-binding protein: An immunohistological study with monoclonal antibodies of human and bovine central nervous system. Proc. Natl. Acad. Sci. USA 83: 3518-3522.

Bignami, A., and B. Delpech (1985) Extracellular matrix glycoprotein (hyaluronectin) in early cerebral development. Int. J. Dev. Neurosci. 3: 301-307.

Bignami, A., L. F. Eng, D. Dahl, and C. T. Uyeda (1972) Localization of the glial fibrillary acidic protein in astrocytes by immunofluorescence. Brain Res. 43: 429-435.

Bignami, A., N. H. Chi, and D. Dahl (1984) First appearance of laminin in peripheral nerve, cerebral blood vessels and skeletal muscle of the rat embryo. Immunofluorescence study with laminin and neurofilament antisera. Int. J. Dev. Neurosci. 2: 367-376.

Bottenstein, J. E., and G. H. Sato (1979) Growth of a rat neuroblastoma cell line in serum-free supplemented medium. Proc. Natl. Acad. Sci. USA 76: 514-517.

Bunge, M. B., R. P. Bunge, D. J. Carey, C. J. Cornbrooks, C. F. Eldridge, A. K. Williams, and P. M. Wood (1983) Axonal and nonaxonal influences on Schwann cell development. In Developing and Regenerating Vertebrate Nervous Systems, P. W. Coates, R. R. Markwald, and A. D. Kenny, eds., pp. 71-105, Liss, New York.

Carey, D. J., and M. S. Todd (1987) Schwann cell myelination in a chemically defined medium: Demonstration of a requirement for additives that promote Schwann cell extracellular matrix formation. Dev. Brain Res. 32: 95-102.

Chiu, A. Y., W. D. Matthew, and P. H. Patterson (1986) A monoclonal antibody that blocks the activity of a neurite regeneration-promoting factor: Studies on the binding site and its localization in vivo. J. Cell Biol. 103: 1383-1398.

Cohen, J., J. F. Burne, J. Winter, and P. Bartlett (1986) Retinal ganglion cells lose response to laminin with maturation. Nature 322 : 465-467.

Cornbrooks, C. J., D. J. Carey, J. A. McDonald, R. Timpl, and R. P. Bunge (1983) In vivo and in vitro observations on laminin production by Schwann cells. Proc. Natl. Acad. Sci. USA 80: 3850-3854.

Davis, G. E., S. N. Blaker, E. Engvall, S. Varon, M. Manthorpe, and F. H. Gage (1987) Human amnion membrane serves as a substratum for growing axons in vitro and in vivo. Science 236: 1106-1109.

Derer, P., and S. Nakanishi (1983) Extracellular matrix distribution during neocortical wall ontogenesis in "normal" and "reeler" mice. J. Hirnforsch. 24: 209-224.

Duffy, P. E. (1982) Glial fibrillary acidic protein and induced differentiation of glia in vitro. J. Neurol. Sci. 53: 443-460.

Eldridge, C. F., J. R. Sanes, A. Y. Chiu, R. P. Bunge, and C. J. Cornbrooks (1986) Basal lamina-associated heparan sulfate proteoglycan in the rat PNS: Characterization and localization using monoclonal antibodies. J. Neurocytol. 15: 37-51.

Eldridge, C. F., M. B. Bunge, R. P. Bunge, and P. M. Wood (1987)
Differentiation of axon-related Schwann cells in vitro. I. Ascorbic acid regulates basal lamina assembly and myelin formation. J. Cell Biol. 105: 1023-1034.

Fairbairn, S., R. Gilbert, G. Ojakian, R. Schwimmer, and J. P. Quigley (1985) The extracellular matrix of normal chick embryo fibroblasts: Its effect on transformed chick fibroblasts and its proteolytic degradation by the transformants. J. Cell Biol. 101: 1790-1798.

Fan, K., and B. G. Uzman (1977) Rat glioma cells $\left(\mathrm{C}_{6}\right)$ cultured in serum-free defined medium. Exp. Cell Res. 106: 397-401.

Ford-Holevinski, T. S., J. M. Hopkins, J. P. McCoy, and B. W. Agranoff (1986) Laminin supports neurite outgrowth from explants of axotomized adult rat retinal neurons. Dev. Brain Res. 28: 121-126.

Grumet, M., S. Hoffman, K. L. Crossin, and G. M. Edelman (1985) Cytotactin, an extracellular matrix protein of neural and non-neural tissues that mediates glia-neuron interaction. Proc. Natl. Acad. Sci. USA 82: 8075-8079.

Hall, S. M. (1986) Regeneration in cellular and acellular autografts in the peripheral nervous system. Neuropathol. Appl. Neurobiol. 12 $27-46$.

Hassell, J. R., W. C. Leyshon, S. R. Ledbetter, B. Tyree, S. Suzuki, M. Kato, K. Kimata, and H. K. Kleinman (1985) Isolation of two forms of basement membrane proteoglycans. J. Biol. Chem. 260: 80988105.

Hatten, M. E. (1987) Neuronal inhibition of astroglial cell proliferation is membrane mediated. J. Cell Biol. 104: 1353-1360.

Hatten, M. E., and C. A. Mason (1986) Neuron-astroglia interactions in vitro and in vivo. TINS 9: 168-174.

Hatten, M. E., M. B. Furie, and D. B. Rifkin (1982) Binding of developing mouse cerebellar cells to fibronectin: A possible mechanism for the formation of the external granular layer. J. Neurosci. 2: 1195 1206.

Ide, C., K. Tohyama, R. Yokota, T. Nitatori, and S. Onodera (1983) Schwann cell basal lamina and nerve regeneration. Brain Res. 288 61-75.

Jones, T. R., E. Ruoslahti, S. C. Schold, and D. D. Bigner (1982) Fibronectin and glial fibrillary acidic protein expression in normal human brain and anaplastic human gliomas. Cancer Res. 42: 168177.

Kavinsky, C. J., and B. B. Garber (1979) Fibronectin associated with the glial component of embryonic brain cell cultures. J. Supramol. Struct. 11: 269-281.

Krayanek, S. (1980) Structure and orientation of extracellular matrix in developing chick optic tectum. Anat. Rec. 197: 95-109.

Krayanek, S., and S. Goldberg (1981) Oriented extracellular channels and axonal guidance in the embryonic chick retina. Dev. Biol. 84 . $41-50$.

Kromer, L. F., and C. J. Cornbrooks (1985) Transplants of Schwann cell cultures promote axonal regeneration in the adult mammalian brain. Proc. Natl. Acad. Sci. USA 82: 6330-6334.

Krystosek, A., and N. W. Seeds (1981) Plasminogen activator release at the neuronal growth cone. Science 213: 1532-1534.

Krystosek, A., and N. W. Seeds (1986) Normal and malignant cells, including neurons, deposit plasminogen activator on the growth substrata. Exp. Cell Res. 166: $31-46$

Kuffler, D. P. (1986) Accurate reinnervation of motor end plates after disruption of sheath cells and muscle fibers. J. Comp. Neurol. 250: $228-235$.

Lander, A. D., D. K. Fujii, and L. F. Reichardt (1985) Laminin is associated with the "neurite outgrowth-promoting factors" found in conditioned media. Proc. Natl. Acad. Sci. USA 82: 2183-2187.

Levi, G., G. P. Wilkin, M. T. Ciotti, and S. Johnstone (1983) Enrichment of differentiated, stellate astrocytes in cerebellar interneuron cultures as studied by GFAP immunofluorescence and autoradiographic uptake patterns with $\left[{ }^{3} \mathrm{H}\right] \mathrm{D}$-aspartate and $\left[{ }^{3} \mathrm{H}\right] \mathrm{GABA}$. Dev. Brain Res. 10: 227-241.

Liesi, P. (1985a) Do neurons in the vertebrate CNS migrate on laminin? EMBO J. 4: 1163-1170.

Liesi, P. (1985b) Laminin-immunoreactive glia distinguish regenerative adult CNS systems from non-regenerative ones. EMBO J. 4: $2505-2511$.

Liesi, P., D. Dahl, and A. Vaheri (1983) Laminin is produced by early rat astrocytes in primary culture. J. Cell Biol. 96: 920-924.

Liesi, P., T. Kirkwood, and A. Vaheri (1986) Fibronectin is expressed by astrocytes cultured from embryonic and early postnatal rat brain. Exp. Cell Res. 163: 175-185. 
Lim, R., D. E. Turriff, S. S. Troy, B. W. Moore, and L. F. Eng (1977) Glia maturation factor: Effect on chemical differentiation of glioblasts in culture. Science 195: 195-196.

Lindsay, R. M., P. C. Barber, M. R. C. Sherwood, J. Zimmer, and G. Raisman (1982) Astrocyte cultures from adult rat brain. Derivation, characterization and neurotrophic properties of pure astroglial cells from corpus callosum. Brain Res. 243: 329-343.

Manthorpe, M., E. Engvall, E. Ruoslahti, F. M. Longo, G. E. Davis, and $S$. Varon (1983) Laminin promotes neuritic regeneration from cultured peripheral and central neurons. J. Cell Biol. 97: 1882-1890.

Margolis, R. U., R. K. Margolis, L. B. Chang, and C. Preti. (1975) Glycosaminoglycans of brain during development. Biochemistry 14 : 85-88.

Matthew, W. D., R. J. Greenspan, A. D. Lander, and L. F. Reichardt (1985) Immunopurification and characterization of a neuronal heparan sulfate proteoglycan. J. Neurosci. 5: 1842-1850.

McCarthy, K. D., and J. de Vellis (1980) Preparation of separate astroglial and oligodendroglial cell cultures from rat cerebral tissue. J. Cell Biol. 85: 890-902.

Michler-Stukc, A., J. R. Wolff, and J. E. Bottenstcin (1984) Factors influencing astrocyte growth and development in defined media. Int. J. Dey. Neurosci. 2: 575-584.

Minier, L. N., R. S. Lasher, and P. F. Erickson (1981) Distribution of the LETS protein (fibronectin) in rat cerebellum. Cell Tissue Res. 214: 491-500.

Moonen, G., Y. Cam, M. Sensenbrenner, and P. Mandel (1975) Variability of the effects of serum-free medium, dibutyryl-cyclic AMP or theophylline on the morphology of cultured new-born rat astroblasts. Cell Tissue Res. 163: 365-372.

Moonen, G., E. Heinen, and G. Goessens (1976) Comparative ultrastructural study of the effects of serum-free medium and dibutyrylcyclic AMP on newborn rat astroblasts. Cell Tissue Res. 167: 221227.

Morrison, R. S., and J. de Vellis (1983) Differentiation of purified astrocytes in a chemically defined medium. Dev. Brain Res. 9: 337345.

Nakanishi, S. (1983) Extracellular matrix during laminar pattern formation of neocortex in normal and reeler mutant mice. Dev. Biol. 95: 305-316.

Noble, M., J. Fok-Seang, and J. Cohen (1984) Glia are a unique substrate for the in vitro growth of central nervous system neurons. J. Neurosci. 4: 1892-1903.

Pittman, R. N. (1985) Release of plasminogen activator and a calciumdependent metalloprotease from cultured sympathetic and sensory neurons. Dev. Biol. 110: 91-101.

Price, J., and R. O. Hynes (1985) Astrocytes in culture synthesize and secrete a variant form of fibronectin. J. Neurosci. 5: 2205-2211.

Raff, M. C., K. L. Ficlds, S.-I. Hakomori, R. Mirsky, R. M. Pruss, and J. Winter (1979) Cell-type-specific markers for distinguishing and studying neurons and the major classes of glial cells in culture. Brain Res. 174: 283-308.

Raff, M. C., E. R. Abney, J. Cohen, R. Lindsay, and M. Noble (1983) Two types of astrocytes in cultures of developing white matter: Differences in morphology, surface gangliosides, and growth characteristics. J. Neurosci. 3: 1289-1300.

Raff, M. C., E. R. Abney, and R. H. Miller (1984) Two glial cell lineages diverge prenatally in rat optic nerve. Dev. Biol. 106: 53-60.

Reier, P. J., L. J. Stensaas, and L. Guth (1983) The astrocytic scar as an impediment to regeneration in the central nervous system. In Spinal Cord Reconstruction, C. C. Kao, R. P. Bunge, and P. J. Reier, eds., pp. 163-195, Raven, New York

Rogers, S. L., P. C. Letourneau, S. L. Palm, J. McCarthy, and L. T. Furcht (1983) Neurite extension by peripheral and central nervous systcm ncurons in response to substratum-bound fibronectin and laminin. Dev. Biol. 98: 212-220.

Schachner, M., G. Schoonmaker, and R. O. Hynes (1978) Cellular and subcellular localization of LETS protein in the nervous system. Brain Res. 158: 149-158.

Selak, I., J. M. Foidart, and G. Moonen (1985) Laminin promotes cerebellar granule cell migration in vitro and is synthesized by cultured astrocytes. Dev. Neurosci. 7: 278-285.

Seregi, A., M. Keller, and G. Hertting (1987) Are cerebral prostanoids of astroglial origin? Studies on the prostanoid forming system in developing rat brain and primary cultures of rat astrocytes. Brain Res. 404: 113-120.

Silver, J., and R. L. Sidman (1980) A mechanism for the guidance and topographic patterning of retinal ganglion cell axons. J. Comp. ncurol. 189: 101-111.

Singer, M., R. H. Nordlander, and M. Egar (1979) Axonal guidance during embryogenesis and regeneration in the spinal cord of the newt: The blueprint hypothesis of neuronal pathway patterning. J. Comp. Neurol. 185: 1-22.

Smith, G. M., R. H. Miller, and J. Silver (1986) Changing role of forebrain astrocytes during development, regenerative failure, and induced regeneration upon transplantation. J. Comp. Neurol. 251: 23-43.

So, K.-F., and A. J. Aguayo (1985) Lengthy regrowth of cut axons from ganglion cells after peripheral nerve transplantation into the retina of adult rats. Brain Res. 328: 349-354.

Sobue, G., and D. Pleasure (1984) Astroglial proliferation and phenotype are modulated by neuronal plasma membrane. Brain Res. 324: $175-179$

Stewart, G. R., and A. L. Pearlman (1987) Fibronectin-like immunoreactivity in the developing cerebral cortex. J. Neurosci. 7: 33253333.

Tomaselli, K. J., L. F. Reichardt, and J. L. Bixby (1986) Distinct molecular interactions mediate neuronal process outgrowth on nonneuronal cell surfaces and extracellular matrices. J. Cell Biol. 103: 2659-2672.

Trimmer, P. A., and K. D. McCarthy (1986) Immunocytochemically defined astroglia from fetal, newborn and young adult rats express $\beta$ adrenergic receptors in vitro. Dev. Brain Res. 27: 151-165.

Vaheri, A., E. Ruoslahti, B. Westermark, and J. Ponten (1976) A common cell-type specific surface antigen in cultured human glial cells and fibroblasts: Loss in malignant cells. J. Exp. Med. 143: 6472 .

Voisin, P. J., J. M. Girault, J. Labouesse, and O. M. Viratelle (1987) $\beta$-adrenergic receptors of cerebellar astrocytes in culture: Intact cells versus membrane preparation. Brain Res. 404: 65-79.

Weibel, M., B. Pettmann, G. Labourdette, M. Miehe, E. Bock, and M. Sensenbrenner (1985) Morphological and biochemical maturation of rat astroglial cells grown in a chemically defined medium: Influence of an astroglial growth factor. Int. J. Dev. Neurosci. 3: 617-630.

Wood, J. N., and B. H. Anderton (1981) Monoclonal antibodies to mammalian neurofilaments. Biosci. Rep. 1: 263-268. 